Article

\title{
Towards Sustaining Levels of Reflective Learning: How Do Transformational Leadership, Task Interdependence, and Self-Efficacy Shape Teacher Learning in Schools?
}

\author{
Arnoud Oude Groote Beverborg ${ }^{1, *}$, Peter J. C. Sleegers ${ }^{1}$, Maaike D. Endedijk ${ }^{1}$ and \\ Klaas van Veen ${ }^{2}$
}

1 Department of Educational Science, Faculty of Behavioural, Management and Social Sciences, University of Twente, P.O. Box 217, 7500 AE Enschede, The Netherlands; E-Mails: p.j.c.sleegers@utwente.nl (P.J.C.S.); m.d.endedijk@utwente.nl (M.D.E.)

2 Department of Teacher Education, Faculty of Behavioural and Social Sciences, University of Groningen, Grote Kruisstraat 2/1, 9712 TS Groningen, The Netherlands;

E-Mail: Klaas.van.Veen@rug.nl

* Author to whom correspondence should be addressed; E-Mail: a.oudegrootebeverborg@utwente.nl; Tel.: +31-53-489-5654.

Academic Editors: Kenneth Leithwood and Jingping Sun

Received: 14 February 2015 / Accepted: 10 March 2015 / Published: 19 March 2015

\begin{abstract}
Whereas cross-sectional research has shown that transformational leadership, task interdependence, and self-efficacy are positively related to teachers' engagement in reflective learning activities, the causal direction of these relations needs further inquiry. At the same time, individual teacher learning might play a mutual role in strengthening school-level capacity for sustained improvement. Building on previous research, this longitudinal study therefore examines how transformational leadership, task interdependence, self-efficacy, and teachers' engagement in self-reflection mutually affect each other over time. Questionnaire data gathered on three measurement occasions from 655 Dutch Vocational Education and Training teachers was analyzed using a multivariate Latent Difference Score model. Results indicate that self-reflection and task interdependence reciprocally influence each other's change. A considerate and stimulating transformational leader was found to contribute to this process. Change in self-efficacy was influenced by self-reflection, indicating that learning leads to competency beliefs. Together, the findings point to the important role transformational leadership practices play in facilitating teamwork, and sustaining teachers' levels of learning in schools.
\end{abstract}


Keywords: transformational leadership; task interdependence; self-efficacy; self-reflection; latent difference score model; vocational education and training

\section{Introduction}

During the past decade, teachers and schools over the globe have been confronted with all kind of changes, including changes in students' demographics, large-scale educational reforms, and accountability policies aimed at improving the quality of education. Building school-wide capacity by promoting teachers' individual and collective learning is considered an important prerequisite for school's ability to change and sustain improvement.

To be able to understand the mechanisms underlying sustained improvement, researchers have started to examine how teacher learning is embedded in schools and linked with building school-improvement capacity [1-5]. In line with this focus, empirical studies into the interplay between leadership, workplace conditions, and psychological factors in teacher learning have been conducted [6-8]. Findings from these studies indicate that both psychological (e.g., self-efficacy, motivation) and organizational factors (e.g., transformational leadership, an open and trustful climate, task and goal interdependence) affect teacher learning such as self-reflection [2,7,9-11]. Moreover, the impact of transformational leadership practices on self-reflection seems to be mediated by both teamwork and teacher motivational factors, including teachers' self-efficacy beliefs $[2,7,8,10]$. More specifically, a recent cross-sectional study has shown how transformational leadership, perceived task interdependence, and self-efficacy are positively related to teachers' engagement in reflective learning activities [12]. Additionally, research has found that teachers' engagement in professional learning activities contributes to changing teachers' instructional practices with the ultimate goal of increasing student achievement [10,13-16].

Although this research has contributed to a deeper understanding of mechanisms underlying educational change and teacher learning in schools, most of the studies are cross-sectional in nature, limiting valid and reliable claims about the direction of influence of the relations found. As cross- sectional estimates may generate misleading interpretations of mediation, longitudinal research can make stronger claims about causality [17-20]. Moreover, longitudinal studies can make an important contribution to a complete understanding of the nature and dynamics of teacher learning as an important catalyst to foster sustained school improvement. Modeling the influences of transformational leadership, task interdependence, and self-efficacy on teachers' reflective learning over time will enable us to both validate previous findings from cross-sectional studies, and investigate possible reciprocal relations undetected by cross sectional models (e.g., [21-23]). For example, sustained engagement in self-reflection, as one of the key professional learning activities of teachers, may help teachers to discover how to benefit from workplace conditions such as being task interdependent. Coming to understand how their team members' knowledge and skills can function as resources, in turn, can then be beneficial to further their own learning (e.g., [24-26]). Additionally, longitudinal research also provides opportunities to investigate the type of change of teachers' engagement in professional learning activities and its antecedents. Levels may be enhanced or declined or sustained, as the result of a variable's (e.g., self-reflection) own dynamics or a coupling with other variables (e.g., transformational 
leadership and self-efficacy), and change rates may differ for individual teachers depending on their previous levels (e.g., [27]). Exploration of these dynamics yields valuable insights in how teacher learning in schools, and its organizational and psychological antecedents, changes over time and what drive their changes. Although different scholars have emphasized the need for using more longitudinal designs in school improvement research [15,28-31] there is still little systematic evidence for how organizational and psychological factors shape teacher learning in the context of the school over time. More longitudinal research is thus needed to increase our understanding of the nature and dynamics of these relationships and how change in schools occurs over time. This study aimed to make a significant contribution to this line of research by conducting a longitudinal study into the nature and dynamics of the paths that link transformational leadership practices, task interdependence, teachers' self-efficacy beliefs, and, consequently, their engagement in self-reflective learning activities (e.g., [2,32]).

The study was conducted within the context of Vocational Education and Training (VET) colleges in the Netherlands. During the past decade, VET colleges have become massive educational institutions due to many mergers and have also been involved in large educational reforms aimed at stimulating students' self-regulated and competence-based learning. One prominent issue in the implementation of these reforms is the reorganization of teachers' working conditions into multidisciplinary teams. Teachers from different disciplines and different subjects are called to collaborate for imparting the competences students need to become strong professionals and thus be better prepared for occupational participation in continuously changing labor market $[7,33,34]$. As a consequence, individual VET teachers are challenged to learn how to work effectively in teams directed at strengthening their professional expertise and, in turn, fostering student learning. The study builds on earlier, cross-sectional, work in which we examined the influence of transformational leadership practices (e.g., vision building, stimulation and consideration), task and goal interdependence as aspects of teamwork, and self-efficacy on teachers' engagement in professional learning activities (e.g., self-reflection, asking for feedback) in Dutch VET colleges [12]. The findings showed two clearly differentiated paths to explain the variation of teachers' engagement in learning activities of which one path leads from a transformational leader that shares a vision, through teachers' perceptions of being goal interdependent, to teachers asking for feedback. As such, asking for feedback seems to be situated in a context of immediate interaction towards a common goal and can be cultivated when a transformational leader keeps sharing the school's vision. The second path leads from a transformational leader who shows consideration for teachers individually, through teachers' perceptions of working together on tasks and their senses of self-efficacy, to teacher self-reflection. These findings suggest that teachers' engagement in self-reflective activities is situated in a context of past experiences of collaboration and can be cultivated through a leader's consideration of needs and individual support. The purpose of this longitudinal study was to investigate whether this latter path that links the relations between transformational leadership practices, task interdependence, self-efficacy, and teacher self-reflection can still be found when assessed over time, thereby validating and extending previous models and findings from cross-sectional research. We also use the added value of a longitudinal design to explore reciprocal relations between these variables, and assess the dynamics of change that occur.

The main research question that guided our research was: How do transformational leadership practices, task interdependence, self-efficacy, and teacher self-reflection mutually shape each other over time? 


\subsection{Theoretical Framework}

An important contribution of our study lies in our attempts to examine changes in transformational leadership practices, task interdependence, teachers' self-efficacy beliefs and their engagement in professional learning activities and how the relationships among these variables evolve over time, by using Latent Difference Score modeling (LDS; see for a more detailed elaboration, below). To understand these relationships, we draw on theories on adult learning, teacher motivation, teamwork and transformational leadership, and use previous findings from cross-sectional research on the interplay between teachers' psychological states and organizational conditions in teacher learning. The model that guided our inquiry is depicted in Figure 1. To test this model, we used data from a sample of 655 Dutch VET teachers. We discuss the variables of our study more fully, and the expected relationship among them in further detail below.

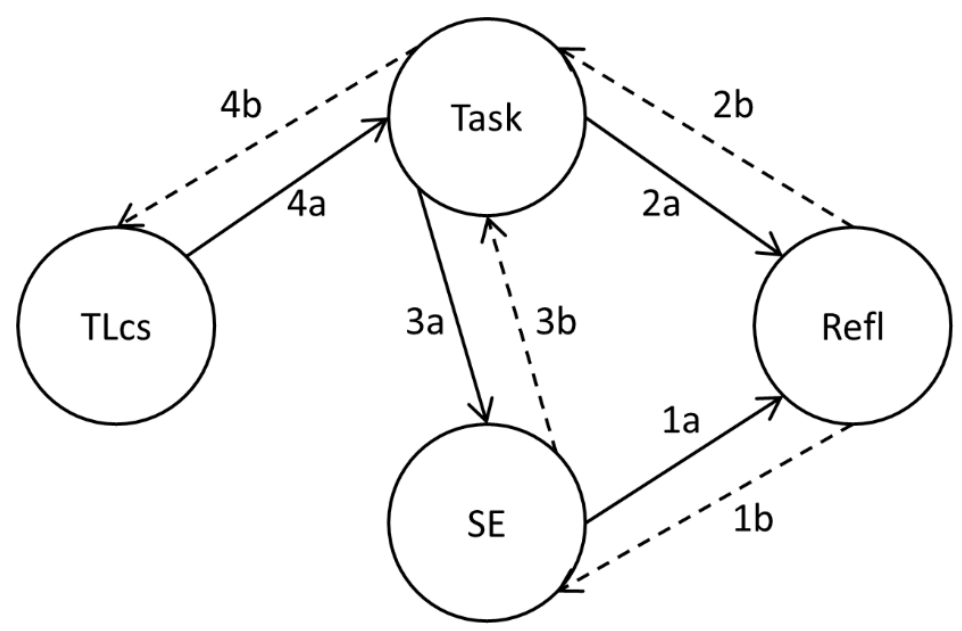

Figure 1. Theoretical framework of how self-reflection (Refl) is influenced by self-efficacy (SE), perceived task interdependence (Task) and the transformational leadership practices individualized consideration and intellectual support (TLcs; solid arrows), as well as the reciprocal relations that will be explored (dashed arrows). The numbers $1 \mathrm{a}-4 \mathrm{~b}$ represent the hypotheses.

\subsubsection{Professional Learning through Engagement in Self-Reflection}

Inspired by adult learning theories and situated cognitive perspective on teacher learning, we conceptualized professional learning as an on-going informal learning process that is embedded within the school and that takes place during the entire career [3,7,35-38]. In line with this perspective, the focus of teacher learning in the context of the school is on teachers' engagement in a variety of professional learning activities aimed at stimulating their own professional development and the development of the school as a whole.

Although scholars have studied a variety of different professional learning activities to capture the content of professional learning (e.g., [7,39]), a distinction between individual and social professional learning activities can be depicted from the literature [7,11,40,41]. Individual learning activities refer to activities aimed to explore and reflect on one's own values, interests, abilities, and career goals, and are carried out individually without any assistance from colleagues or supervisors. Examples of individual 
learning activities are reflecting on past performances, reading professional material, and focusing on future career goals. Social learning activities refer to activities aimed at acquiring new knowledge, skills, information and ideas that are acquired in social interaction with others. Examples of social learning activities are sharing knowledge, asking for feedback and challenging groupthink. Although both types of learning activities are ways to discover the proper script for future actions and are nested in a social context, the sources and thereby the nature of these learning activities thus differ. As indicated, in this study we focus on self-reflection as one of the most important individual learning activities teachers are engaged in during their daily practice $[35,42]$.

Self-reflection is an introspective activity and refers to a person recreating the experience of acting in a given situation. In "reliving" this experience a person supplements the memory of the experience with new ideas that can either be self-generated or based on information gained from others. This creates an altered and thus new experience, which can then serve as the basis for future action (e.g., [43]). Self-reflection allows teachers to broaden their teaching repertoire, generate new knowledge, and make knowledge explicit aimed at discovering a workable script for adaptation to changing circumstances [35,42]. These adaptations may in turn fuel continuance of individual teachers' own reflections [1], and can be of value for team members [11], as knowledge gained through self-reflection can be made explicit and shared. Moreover, as circumstances continuously change old solutions expire, and hence sustained levels of engagement in self-reflection are important for maintaining high levels of craftsmanship [44,45]. Newly generated knowledge can be experimented with to fit to changed circumstances $[46,47]$. Research has shown that self-reflection contributes to changing instructional practices, and in turn improved student performance [7,10,13-15,48]. The importance of teacher reflection for improving the quality of education therefore leads to the question how to facilitate reflection, and how to sustain sufficient levels of learning over time [49,50].

\subsubsection{Self-Efficacy Beliefs}

Self-efficacy represents the level of competence a person expects to display in a given situation. Self-efficacy develops, for instance, from coping with various difficult and complex situations successfully as the experience of mastery is one of the most important sources of self-efficacy, next to modeling or vicarious experiences, social persuasion, and physiological and emotional states [51]). In addition, repeatedly perceiving team members resolving problems can facilitate the development of a teacher's own self-efficacy through vicarious learning or modeling. Persons with higher levels of self-efficacy will persist in the face of difficulties, feel empowered, are less constraint by doubts, and will thus arrive quicker at a satisfying solution $[52,53]$.

Cross-sectional research has shown that teachers who have higher levels of self-efficacy are more engaged in learning activities (e.g., self-reflection) that may challenges existing knowledge, beliefs, and classroom practices than their colleagues with lower levels of self-efficacy [2,10,54-56]. Additionally, longitudinal research indicates that self-efficacy has predictive power over time on levels of vigor and dedication of teachers [57], as well as on changing instructional practices [15]. Interestingly for the present study, empirical evidence suggests that self-efficacy is not a stable phenomenon: it grows in primary school children [58], declines in adolescents [53], and fluctuates in teachers [31]. To what extent teachers' beliefs in their self-efficacy changes, and the manner in which these changes relate over 
time to engagement in self-reflection, has yet to be addressed. It seems however likely that increases in beliefs about their own effectiveness motivate teachers to meet challenges, and thereby may positively affect their engagement in professional learning activities over time. Additionally, reflection may also impact self-efficacy. Generating knowledge to adapt to changing circumstances helps to resolve problems and come to satisfying solutions. Sustained levels of self-reflection can therefore lead to mastery experiences, and thus help to develop beliefs of self-efficacy, which makes it worthwhile to explore whether a bidirectional link between these variables can be found. As only a few available studies have examined this reciprocal relationship [51,59], more research is needed. Based on previous cross-sectional studies, we expect that higher reported levels of self-efficacy will increase teachers' engagement in self-reflection (Hypothesis 1a). In line with the outcomes of the few available studies studying the reciprocal relationship [51,59], we also hypothesize that as teachers' engagement in self-reflection increases over time, their self-efficacy beliefs will also increase (Hypothesis 1b).

\subsubsection{Perceived Task Interdependence}

Task interdependence refers to the perceived degree of interaction between team members required to complete tasks. Thus, task interdependence can be seen as providing the infrastructure needed to stimulate teacher interaction as well as the exchange of information and resources for successful task completion [60-63]. Research on the role of collaboration between teachers for promoting professional learning has provided evidence for the positive impact of teacher interaction on teacher learning, and, in turn, enhance team effectiveness [34,64]. Because teachers can use knowledge that team members have made explicit as input for their own reflection, interacting with team members facilitates teacher engagement in self-reflective activities $[39,55,65]$. In addition, teachers' self-efficacy beliefs have been shown to mediate the effect of teacher interaction on professional learning and vigor and dedication of teachers $[2,10,57]$ by removing uncertainty and ambiguity [66]. Collaboration and teacher interaction can thus offer teachers an "efficacy boost" [67], thereby facilitating their engagement in professional learning activities. Although these findings make it likely that perceptions of task interdependence have a positive impact on engagement in self-reflection and self-efficacy beliefs, we know little about how interactions with peers who are directly engaged in the same task affect teachers' sense of self-efficacy and their self-reflective activities over time.

As teachers need time to come to understand how to interact with colleagues to complete tasks, generating knowledge to adapt to changing circumstances might help [68,69]. When teachers find adequate ways to interact with each other, obtained knowledge from colleagues can be beneficial to further promote their own learning [13,24-26]. Additionally, enhanced efficacy beliefs about resolving conflict in teams through vicarious team experience have been found to positively affect expected outcomes of teams [70]. Therefore, self-efficacy may also influence change in perceptions of task interdependence: having a more positive view of intra-team conflict and having confidence that conflicts will be resolved may lead to more frequent and more positive interactions. Teachers may thus come to value more interdependence in working on tasks. In this study, we therefore hypothesize that higher levels of perceived task interdependence will increase teachers' engagement in self-reflection (Hypothesis 2a). Based on a more dynamic representation of the assumed associations between these variables, we also expected that as teachers' engagement in self-reflection increases over time, perceived 
task interdependence would also increase (Hypothesis 2b). In addition, we hypothesize the time-based dynamic relations between self-efficacy and task interdependence as follows: as teachers perceive higher levels of perceived task interdependence, higher level beliefs about their own self-efficacy are expected to follow (Hypothesis 3a) and vice versa (Hypothesis 3b).

\subsubsection{Transformational Leadership}

Leadership is widely assumed to play a major role in the promotion of school improvement efforts and educational change, particularly when the leadership is characterized as what is called "transformational leadership" [71]. A transformational leader aims at development in a context of organizational change and is committed to the empowerment of individual teachers and teacher teams as a whole [32,72-75]. Three transformational leadership dimensions have been found critical for the enhancement of individual learning activities [76]. The first dimension of initiating and identifying a vision refers to a leader who works on the development of shared goals and priorities by inspiring teachers to formulate shared goals, connect to these, commit to them, and try to attain them. The second dimension of individualized consideration refers to support and attention for individual needs and feelings. Teachers should feel empowered by a considerate transformational school leader and - as a consequence - seek to interact with other teachers and coordinate responsibility in the tasks they share [2,77]. Intellectual stimulation as the third dimension of transformational leadership involves the encouragement of teachers to continuously calibrate the adequacy of their knowledge and instructional practices. It tries to incite a critical attitude towards oneself and one's team members through the idea that not one solution is absolute, that there are alternatives to problems, and that conflict can be functional for effective teamwork. As such, it can improve team-work by enhancing teachers' abilities to solve individual, group and organizational problems [2,77].

Whereas the three dimensions of transformational leadership would appear to directly influence self-efficacy and teacher learning (e.g., [15,78,79]), empirical research that addressed these effects did not consistently find these effects, however (e.g., [80,81]). Instead of a direct link, it seems more likely that the relation between transformational leadership on the one hand, and self-efficacy and self-reflection on the other hand, is mediated by perceptions of workplace conditions (e.g., [2,10,82-84]). Previous studies have indeed found that transformational leadership practices are related to various workplace conditions and have an initiating role in enhancing these conditions (e.g., [85]).

In addition, it has recently been shown that transformational school leadership can enhance the prerequisites for perceiving interdependence-including teacher collaboration and trust $[10,86]$. In our previous cross-sectional research on the impact of transformational leadership practices on teamwork, self-efficacy and teacher learning in VET colleges, we have found that individualized consideration and intellectual stimulation affect task interdependence directly, while vision building did not. Moreover, it appeared that the influence of transformational leadership on teachers' efficacy beliefs and self-reflection was mediated by perceived task interdependence [12]. Although the few available studies provide some evidence for the relationship between teamwork processes, especially perceived task interdependence, and two of the three dimensions of transformational leadership, including individualized consideration and intellectual stimulation, more research is needed to assess how these transformational 
leadership practices affect perceptions of task interdependence over time, thereby validating and expanding previous findings.

Furthermore, a bi-directional link between transformational leadership and task interdependence seems likely. In the long term, building teacher craftsmanship, may distribute the sources of leadership in a school from one (or few) to many sources. Leadership may diffuse first through the team, and finally through the organization $[29,87]$. Interacting and collaborating with colleagues might contribute to this process, because it elevates levels of potentially useful knowledge individual teachers and teacher teams may use to become more proficient. Based on the aforementioned, we therefore hypothesize that as transformational leadership practices (e.g., individual consideration and intellectual stimulation) increase over time, teachers' perceptions of their task interdependence would also increase (Hypothesis 4a). In addition, as interacting and collaborating with colleagues might contribute to more distributive forms of leadership, we expected that higher levels of perceived task interdependence would lead to slow changes in transformational leadership over time (Hypothesis $4 \mathrm{~b}$ ).

\subsection{The Present Study}

The aim of the present study is to longitudinally assess the mutual relations between transformational leadership (i.e., individualized consideration and intellectual stimulation), perceived task interdependence, self-efficacy, and teachers' engagement in self-reflection over time.

On the basis of findings from previous studies, we formulated four hypotheses regarding the reciprocal relations between self-reflection, self-efficacy, task interdependence and the transformational leadership practices individualized consideration and intellectual support. These hypotheses are visualized in Figure 1. We tested these assumed dynamic associations between our variables, using data gathered on three yearly-based measurement occasions from 655 Dutch Vocational Education and Training teachers. As such, this study will make a unique contribution to a deeper understanding of the dynamics and complexities underlying sustainable school improvement.

\section{Method}

In order to assess the time-based dynamics of the relationship between these variables, we used Latent Difference Score (LDS) modeling [20,27,88]. LDS modeling, derived from dynamic system theory [27], is a form of Structural Equation Modeling (SEM), and combines cross-lagged regression analysis and latent growth curve modeling. This allows for the modeling of dynamic intra-individual change. Dynamic modeling of this nature provides opportunities to explore and test the hypothesized reciprocity of the relationships amongst the variables examined in our study by illustrating how changes in one variable (e.g., self-reflection) over time depend on the state of another variable (e.g., self-efficacy, and task interdependence) and any prior change in the system as a whole. Details regarding sample, measures and analytic strategy are described below.

\subsection{Sample}

Data were collected from teachers of interdisciplinary teams from the various departments of six VET colleges (e.g., a technology department, an economics and business department, a health and welfare, 
department, an education department). The interdisciplinary teams within these departments were responsible for the coaching of a specific group of students, the guidance of their learning processes, the planning of the curricula for the group and assessment of their progress.

We used convenience sampling to obtain a sample as large as possible. The six VET colleges were contacted via their boards of directors. For two of the colleges, the teachers were contacted directly to invite them to participate in the present study. For the other four colleges, the team leaders were asked if their teams would be willing to participate. Questionnaires were sent to the teachers of the teams that were willing to participate. To maximize responding, we informed each team about the goals of our research, told them about the content of the questionnaire and offered to give a presentation on the main findings once the study was completed.

The questionnaires were administered using the online program "survey monkey". During three years (from 2010 to 2012), questionnaires were sent to more than 800 teachers. On each measurement occasion about 400 returned the questionnaire, with response rates of $53 \%, 52 \%$, and $47 \%$ for the three sequential occasions. Not all returned questionnaires could be used for further analysis, because, for example, respondents did not fill out the questionnaire completely. Subsequent analyses are based on the data of 655 unique respondents, of which 144 responded on all three occasions, 181 responded on two occasions, and 330 responded on only one occasion. Moreover, Mplus, the software we used to analyze the data with, provides maximum likelihood estimation for missing data, and it computes the standard errors for the parameter estimates using the observed information matrix [89]. See Appendix 1 for a more detailed description of the responses.

Over three measurement occasions with one year intervals and of all the teachers who responded, the average age was 48 years (standard deviation of 10). The majority of the respondents worked more than $32 \mathrm{~h}$ per week (about 60\%). Many of the respondents had worked as a teacher for more than 20 years (32\%); a sizeable percentage had worked around 10 years as a teacher $(21 \%)$. Most of the teachers had a bachelor's degree (72\%); 16\% had a master's degree; and 12\% had completed only a secondary level of education. See Appendix 2 for a more detailed description of the sample on the three measurement occasions.

\subsection{Measures}

The following variables were assessed using already existing, well-validated measurement scales: transformational leadership individualized consideration and intellectual stimulation (11 items) $[2,10,12]$, task interdependence (4 items) $[9,12,55,63]$, occupational self-efficacy (6 items) $[9,12,55,90]$, and self-reflection (5 items) $[9,12,42,55]$. Teachers indicated the extent to which the item content applied to them on five-point scales $(1=$ strongly disagree, $2=$ partially disagree, $3=$ do not disagree, do not agree, $4=$ partially agree, $5=$ strongly agree). The items in the questionnaire referred to the above mentioned concepts (see Appendix 3 for an overview of the scaled variables and related items).

As mentioned earlier, two dimensions of transformational leadership, including individualized consideration and intellectual stimulation, were measured based on previous cross-sectional research [2,10,12]. Individualized consideration was defined as the extent to which the school leader acknowledges teachers' efforts, provides individualized support for teachers and was measured using five items. The second scale, providing intellectual stimulation, consisted of six items and concerned the 
degree to which the school leader provides teachers with intellectual stimulation. The reliability of these subscales has been found to be satisfactory [2,10,12,15]: Cronbach's alpha coefficients for individualized consideration varied from 0.87 to 0.93 and for intellectual stimulation from 0.88 to 0.94 .

Task interdependence refers to the extent to which teachers perceive that the interaction and coordination of team members is required to complete tasks (four items). Cronbach's alpha coefficients, ranging from 0.70 to 0.79 , have been reported in literature $[12,55,63]$.

Occupational self-efficacy was defined as the extent to which teachers have a future-oriented belief about their level of competence that they expect to display in a given situation. This scale consists of six items. The reliability of this scale has been found to be satisfactory $[9,12,55]$ : Cronbach's alpha coefficients for occupational self-efficacy varied from 0.75 to 0.80 .

Teachers engagement in self-reflection refers to the extent to which teachers are engaged in individual activities aimed at making implicit knowledge explicit (5 items). Cronbach's alpha coefficients, ranging from 0.72 to 0.82 have been reported in the literature $[9,12,55]$.

In preliminary analysis we first conducted confirmatory factor analysis per variable on all three measurement occasions, using Mplus 7.1 [89]. The findings showed that, for all three measurement occasions, the items loaded well on their factors.

Second, we investigated whether the variables were longitudinally valid by testing models with unrestraint factor loading per item on each of the three measurement occasions, versus models in which each item's factor loading was constraint to be equal over time [91]. The findings showed that our measures were invariant, and the latent or true scores of the variables could be separated from the random error of measurement. Moreover, all variables significantly predicted themselves over time, indicating that they were stable (see Appendix 4).

Finally, we constructed a measurement model to assess whether the theoretical constructs (factors) such as we measured them fitted well to the data in relation with one another. To obtain factor means we had to apply the assumption of measurement error with means of 0 . The findings showed an acceptable fit of the model to the data, $\chi^{2}(2977)=6055.275(p=0.000)$, RMSEA $=0.040$, CFI $=0.838$, $\mathrm{SRMR}=0.073$. The items and their parameter estimates (i.e., factor loadings and residual variances) are presented in Appendix 3, and the means, standard errors of the means, and the correlations between all variables at all measurement occasions are presented in Appendix 5.

\subsection{Analytic Strategy}

As indicated above, we analyzed the data from this study using Latent Difference Score (LDS) structural equation modeling programmed in Mplus 7.1 [89]. The key elements of an LDS approach are the variables' latent difference factors, which specify the variable's change score at each time point (see for instance $[92,93])$. Unique in the LDS approach is that this change score consists of two components:

1. A constant change component, which is a constant underlying growth parameter or the underlying constant slope (latent slope);

2. A proportional change component, which is the autoregressive coefficient [27].

Together they form the so-called dual change score model, in which both components together model the intra-individual change. Changes in the LDS model accumulate over subsequent time 
points $[20,27,94]$. For the reader's complete understanding, a bivariate dual change Latent Difference Score (LDS) model, is visualized and discussed briefly in Appendix 6.

The dual change model (constant change and proportional change) might not be the model that fits best to the intra-individual change present. For example, if the variables do not show a constant increase (or decline) within the timeframe that was measured, a model including only the proportional change component will fit the data better than the full dual change model. As a first step in our analysis we, therefore, tested for every variable separately (univariate LDS model) which type of change model fitted the data best. We tested three versions of the univariate LDS models against each other [18]:

1. an LDS model with invariant autoregressions and a latent slope (dual change model) against an LDS model with freed autoregressions and without a latent slope (proportional change model);

2. an LDS model with invariant autoregressions and a latent slope (dual change model) against an LDS model without autoregressions and with a latent slope (constant change model);

3. an LDS model without autoregressions and with a latent slope (constant change model) against an LDS model with freed autoregressions and without a latent slope (proportional change model).

The models were compared using the Chi-square difference $\left(\Delta \chi^{2}\right)$ test with degrees of freedom $(d f)$ equal to the difference in numbers of parameters left free for estimation. Additionally, a good fit of a model to the data is indicated by a Chi-square $\left(\chi^{2}(d f)\right)$ that is not significant, an RMSEA (Root Mean Square Error of Approximation) $\leq 0.06$, a CFI (Comparative Fit Index) $>0.95$, and an SRMR (Root Mean Square Residual) $\leq 0.08$ [95]. After selection of the best fitting models we performed subsequent analyses to see whether better fits were obtained by freeing or constraining other parameters.

In the second step we extended the best fitting univariate change score model to multivariate LDS models. As multiple variables are included, the initial factors and slope factors of different variables will also be correlated. More interesting however are the coupling parameters ( $\gamma$ 's, see Appendix 6 ) between difference factors at time $t$ and measurement occasion factors at time $t-1$. These coupling parameters may be in one direction, but the coupling may also be bidirectional, such that reciprocity between variables becomes a testable property of the model. The couplings relate variables on all occasions, that is, they are now dynamically related. This means that a variable's change depends on the variable's level at a previous time point and on a systematic growth rate, as well as, when coupled with another variable, on the level of the other variable at a previous time point. Change patterns therefore depend on the presence of these parameters, and even when parameter values are constant over time non-linear trajectories may be obtained (see for an example [93]). The parameters are interpreted together, because they jointly bring about the dynamics of the system [27]. For testing our hypotheses, the coupling parameters are studied because they test for the prediction (over time) of one variable (e.g., self-efficacy) on another (e.g., self-reflection), and therefore strengthen claims of causality, and provide a strong basis for claims of mediation [18,20]. Moreover, these predictions are independent of outcome variables' histories.

In order to explain the multivariate LDS model we used Mplus 7.1 [89] to test the dynamics of the assumed paths that link the variables in our study (see Figure 1). The multivariate model was assessed in three steps. First, the variables were modeled in a "straightforward" causal manner, based on findings from our previous cross-sectional research. Second, corresponding "reversed causal" coupling parameters were added to assess the reciprocal relations between variables. Third, on the basis of the 
principle of parsimony, non-significant effects were removed from the model. More detailed information about the Mplus codes used, are available on request by the first author.

\section{Results}

\subsection{Univariate Model Selection}

We started our data analysis with examining which univariate LDS models fitted best the intra-individual change of each variable in our study. As mentioned earlier, we tested three versions of the univariate LDS models against each other. These tests indicated for all variables that the proportional change models (model with freed autoregressions and without a latent slope) fitted the data best (see for Model selection and $\Delta \chi^{2}$ tests Appendix 7). This means that overall the variables did not show a constant increase (or decline) within the timeframe that we measured.

Subsequent tests to assess whether the models would fit the data better if their proportional change parameters were held invariant [18], indicated this to be the case for self-reflection, self-efficacy, and task interdependence. Subsequent tests showed that levels of self-reflection declined between occasion 1 and $2\left(\mu_{\text {Refl } 2}-\mu_{\text {Refl1 }}=-0.072, p=0.015\right)$, after which its level was sustained, self-efficacy increased between occasion 1 and $2\left(\mu_{\mathrm{SE} 2}-\mu_{\mathrm{SE} 1}=0.057, p=0.045\right)$, after which its level was sustained, task interdependence remained constant, and that consideration and support increased between occasion 1 and $2\left(\mu_{\mathrm{TLcs} 2}-\mu_{\mathrm{TLcs} 1}=.123, p=0.024\right)$, as well as between occasion 2 and $3\left(\mu_{\mathrm{TLcs} 3}-\mu_{\mathrm{TLcs} 2}=0.088\right.$, $p=0.041) .{ }^{1}$ But despite that the values of consideration and stimulation appear incremental they are not constant enough to prefer a model with a constant change factor (i.e., a dual change model) over a proportional change model (as indicated by the results of the model comparisons). Univariate proportional change models, their values, fit measures, as well as their corresponding trajectories, are presented in Appendix 8.

\subsection{Testing the Multivariate Model}

Based on these findings, we subsequently examined the dynamic relationships between the variables of our study with a multivariate proportional change model. The coupling parameters are of primary interest, as they provide the evidence for causal relations.

A four-variable proportional change model was fit to the data. The included variables were consideration and stimulation, perceived task interdependence, self-efficacy, and self-reflection. In this first model only those unidirectional coupling parameters were included that had been found in our previous cross-sectional study, resulting into a path that led from a transformational leader who

1. Because proportional change models were selected (and not dual change models), the equation to calculate difference scores with is the following:

$$
\Delta \mathrm{Yit}=\mu_{\Delta 1}+\beta \mathrm{Y} * \text { Yit-1 }
$$

where $\mu_{\Delta t}$ is the estimated intercept of the difference score at a certain occasion. To test whether measurement occasion scores significantly differ from occasion to occasion, measurement occasion scores are compared. Measurement occasion scores are calculated by adding an occasion's difference score and its previous measurement occasion score. 
shows consideration for teachers individually and stimulate teachers intellectually, through teachers' perceived task interdependence (Hypothesis 4a), to self-efficacy (Hypothesis 3a), and self-reflection (Hypothesis 1a and $2 \mathrm{a}$ ). The fit of the model to the data was acceptable: $\chi^{2}(3028)=6222.830$ $(p=0.000), \mathrm{RMSEA}=0.040, \mathrm{CFI}=0.832, \mathrm{SRMR}=0.084$. In the second model reciprocal relations were included. We therefore added the "reversed causal" coupling parameters from task interdependence to consideration and stimulation (Hypothesis 4b), from self-efficacy to task interdependence (Hypothesis 3b), from self-reflection to task interdependence (Hypothesis 2b), and from self-reflection to self-efficacy (Hypothesis 1b). The fit of this second, modified, model to the data was acceptable: $\chi^{2}(3024)=6207.606(p=0.000)$, RMSEA $=0.040, \mathrm{CFI}=0.832, \mathrm{SRMR}=0.082$, and this less restraint model fitted the data better than the first model: $\Delta \chi^{2}(4)=15.224(p=0.004)$. Based on the principal of parsimony, we removed the following non-significant coupling parameters from the second model: from self-efficacy to self-reflection (Hypothesis 1a), from self-efficacy to task interdependence (Hypothesis 3b), from task interdependence to self-efficacy (Hypothesis 3a), and from task interdependence to consideration and stimulation (Hypothesis $4 \mathrm{~b}$ ). This resulted in a third model with an acceptable fit: $\chi^{2}(3028)=6213.389(p=0.000), \mathrm{RMSEA}=0.040, \mathrm{CFI}=0.832, \mathrm{SRMR}=0.083$, and this more parsimonious model fitted the data as well as the less restrained second model: $\Delta \chi^{2}(4)=5.783$ ( $p=0.216$ ). Allowing the coupling parameters to be variant did not improve the fit of the model to the data. Parameter values of the third, parsimonious multivariate LDS model are presented in Table 1. For complete understanding, the correlations between the initial factors and the coupling parameters of this third model are presented in Figure 2.

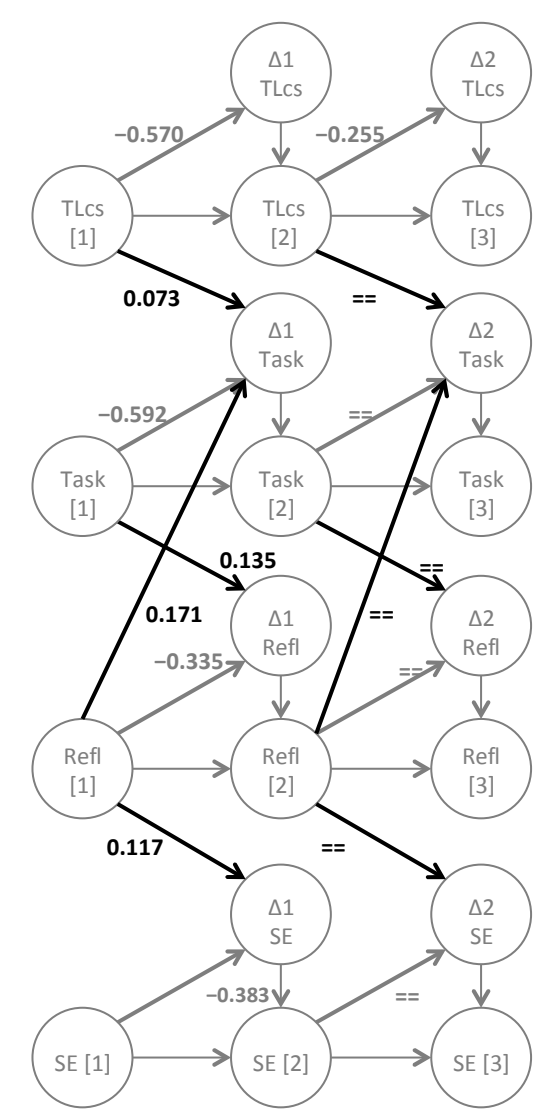

Figure 2. Simplified representation of the parsimonious multivariate proportional change Latent Difference Score (LDS) model. 
Values in the figure are significant. TLcs = transformational leadership consideration and stimulation; Task = task interdependence; $\mathrm{SE}=$ self-efficacy; Refl = self-reflection. TLcs[t] represents its measurement occasion factor at time t. $\Delta[\#]$ TLcs represents its latent difference factors for subsequent occasions. The black single headed arrows are the invariant couplings from one variable to another (the $\gamma$ 's) with their values. The double equality signs represent invariance. The bold grey arrows are the autoregressions $(\beta$ 's) with their values. The grey arrows without values are fixed at 1 . TLcs does not have invariant autoregressions, Task, SE, and Refl do. The model is simplified to stress the influences over time and to ease interpretation.

As can be seen in Figure 2, the most parsimonious model indicates:

- a leading role of consideration and stimulation on perceived task interdependence (Hypothesis 4a);

- reciprocity between task interdependence and self-reflection (Hypothesis 2a and 2b);

- a peripheral role of self-efficacy, as only the level of self-reflection influenced the levels of self-efficacy, but not vice versa.

This final model explained $37.3 \%$ of the variance of the first latent difference score of consideration and stimulation, and $13.6 \%$ of its second, $28.8 \%$ of task interdependence's first and $27.5 \%$, of its second, $23.8 \%$ of self-efficacy's first, and $14.5 \%$ of its second, and $14.0 \%$ of self-reflection's first, and $17.3 \%$ of the variance of its second latent difference score.

Values in the table are significant. Double equality signs indicate that this parameter was held invariant. $N=655$, number of free parameters $=131$. TLcs $=$ transformational leadership consideration and stimulation; task = task interdependence; $\mathrm{SE}=$ self-efficacy; Refl = self-reflection. Factor loadings from the measurement occasion factors are not listed. See therefor Appendix 3. Error variances are not listed. See for an approximation Appendix 3. Error variances from the final structural model deviate from those in the measurement model with a maximum of 0.004, 0.003, 0.006, and 0.007 for TLcs, Task, SE, and Refl, respectively.

We will elaborate on the most important findings from the parsimonious multivariate LDS model by first giving interpretations of the initial levels from each variable, followed by our interpretations of the parameters relating the variables (following the order of the parameters in Table 1). Change of the separate variables was already discussed in the univariate model selection section (see autoregressions and difference factors intercepts in Table 1 and Appendix 8).

All initial factor means were significant (see $\mu_{1}$ in Table 1). Consideration and stimulation's initial factor mean was above average (about 3.7 on a 5-point scale). Self-efficacy's initial factor mean was high, and task interdependence's and self-reflection initial factor means were very high (all above 4 on a 5-point scale).

All initial mean factors were significantly and positively correlated (see $\rho$ 's in Table 1), suggesting that higher perceptions of consideration and stimulation of the transformational leader co-occurred with higher perceptions of task interdependence, higher beliefs in efficacy, and higher engagement in self-reflective activities, at the onset of the study (first measurement occasion). 
Table 1. Parameter estimates from the final multivariate latent proportional change score model.

\begin{tabular}{ccccc}
\hline Parameter & TLcs & Task & SE & Refl \\
\hline Autoregression (proportion) $\beta_{1}$ & -0.570 & -0.592 & -0.383 & -0.335 \\
Autoregression (proportion) $\beta_{2}$ & -0.255 & $==$ & $==$ & $==$ \\
Initial mean $\mu_{1}$ & 3.676 & 4.551 & 4.087 & 4.346 \\
Difference factor1 intercept $\mu_{\Delta 1}$ & 2.216 & 1.634 & 1.112 & 0.768 \\
Difference factor2 intercept $\mu_{\Delta 2}$ & 1.058 & 1.621 & 1.064 & 0.820 \\
Coupling $\gamma$ & & & & \\
TLcs[t- $\Delta \mathrm{t}] \rightarrow \Delta$ Task[t] & & 0.073 & & \\
Refl[t- $\Delta \mathrm{t}] \rightarrow \Delta$ Task[t] & & 0.171 & & \\
Refl[t- $\Delta \mathrm{t}] \rightarrow \Delta$ SE[t] & & & 0.117 & \\
Task[t- $\Delta \mathrm{t}] \rightarrow \Delta$ Refl[t] & & & & 0.135 \\
Initial variance $\phi_{1}{ }^{2}$ & 1.051 & 0.259 & 0.261 & 0.236 \\
Difference factor1 variance $\omega_{\Delta 1}{ }^{2}$ & 0.574 & 0.182 & 0.097 & 0.136 \\
Difference factor1 variance $\omega_{\Delta}{ }^{2}$ & 0.316 & 0.221 & 0.169 & 0.132 \\
Correlations $\rho$ & I TLcs & I Task & I SE & I Refl \\
I TLcs & 1 & & & \\
I Task & 0.126 & 1 & & \\
I SE & 0.119 & 0.089 & 1 & \\
I Refl & 0.063 & 0.099 & 0.122 & 1 \\
\hline
\end{tabular}

The variables were related over time in the parsimonious multivariate LDS model through four significant, and invariant, coupling parameters (see Figure 2, and $\gamma$ 's in Table 1). The first coupling parameter is from consideration and stimulation to task interdependence. Intra-individual increases in a transformational leader's consideration and stimulation practices lead to intra-individual increases in perceptions of the need to interact to complete tasks. This supports our Hypothesis 4a. The second coupling parameter is from task interdependence to self-reflection, and the third is from self-reflection to task interdependence. Intra-individual increases in perceptions of the need to interact to complete tasks lead to intra-individual increases in engagement in self-reflective actions, as well as vice versa. As we hypothesized (Hypotheses $2 \mathrm{a}$ and $2 \mathrm{~b}$ ), task interdependence and self-reflection are thus reciprocally related. The fourth coupling parameter is from self-reflection to self-efficacy. Intra-individual increases in engagement in self-reflective actions lead to intra-individual increases in beliefs of competence (Hypothesis 1b).

Overall these results show a leading role of the transformational leadership practices consideration and stimulation. Task interdependence was found to be directly influenced by consideration and stimulation. Task interdependence and self-reflection were found to have reciprocal roles in sustaining each other's levels. Surprisingly, self-efficacy was only coupled to self-reflection, and levels of self-efficacy were sustained by levels of self-reflection.

\section{Discussion}

The present investigation tested the longitudinal effects of transformational leadership practices (i.e., consideration and stimulation), perceptions of task interdependence, and self-efficacy beliefs, on VET teachers' engagement in self-reflection. In addition, possible reciprocal relations between these 
variables were explored. Data of three measurement occasions with yearly intervals from a total of 655 participants were used for the analyses. Each variable was analyzed with univariate LDS models to assess their change. To analyze the time-based dynamic relations between the variables, a multivariate LDS model was tested. As the LDS approach enables us to represent dynamic relations between our variables over time, this approach can be considered as a strong and innovative approach for examining the role teacher learning may play in building school's capacity to change and sustained improvement.

None of the variables showed systematic constant change. Interestingly reflection declined between measurement occasion 1 and 2, after which its (still high) level was sustained. The decline on the second measurement occasion might indicate that teachers had become more critical on their own levels of reflection. However, such a critical attitude did not result in sustained decline. To understand more about the process through which self-reflection progresses, future studies must address self-reflection not only in terms of an activity, but also in terms of the content that is reflect on, to distinguish reflection on reflection from reflection to improve, for instance, instructional practices. Levels of self-efficacy were found to increase between occasion 1 and 2, after which they remained stable. These findings partly concur with findings from previous studies into the variability of teacher self-efficacy [31,96,97]. These findings showed variability in teacher-self-efficacy according to contextual (i.e., student groups) and person (i.e., teacher) effects as well as quite stable effects over time. More research is needed to increase our knowledge on the variability of teacher self-efficacy, using more time-intense intervals; for example monthly or weekly-based time intervals instead of yearly-based (e.g., [53]). Task interdependence did not change. This may be the most surprising finding of this study, as we expected that teachers' perceptions of task interdependence would have increased after the implementation of multidisciplinary teams in VET colleges. However, the finding that initial levels of task interdependence were already very high might indicate that teachers had welcomed an infrastructure that facilitated more contact with colleagues (e.g., [5,69]). Although consideration and stimulation increased over time, we did not find a systematic constant change factor. Apparently, after the initiation of teams, and over the course of the study, school leaders seem to attend to individual teachers' needs and feelings more, and challenged their beliefs, values, and practices more.

All four variables' initial factors were significantly and positively correlated. This suggests that those teachers scoring higher on any one variable tend to score higher in all other variables at the onset of the study. This means that people who reflect more, have higher levels of self-efficacy, perceive more interaction with team members to complete tasks, and also perceive their leader to be more considerate and more stimulating. Thus, higher personal and organizational resources that are assumed to be beneficial to take charge of change tend to go together.

Variables were sustained by the influence of other variables, but not all our hypotheses were confirmed. First, contrary to our hypothesis (Hypothesis 1a), self-efficacy did not influence self-reflection: the coupling parameter from self-efficacy to self-reflection was not significant This finding is not in line with previous cross-sectional findings which have suggested that self-efficacy beliefs are a critical component for self-reflection [2,15]. Furthermore, it contrasts with the claim that self-efficacy has a pivotal role as a psychological lever between leadership and performance [98], at least when performance consists of the generation of new knowledge. As such, the assumed causal influence of self-efficacy on self-reflection seems not to withstand the test of time. One explanation may be that teachers with high sustained levels of self-efficacy are less motivated to learn. As they already feel 
excessively confident, they may think that they have nothing left to learn. However, we did find the reversed effect (Hypothesis 1b): self-reflection had a positive influence on self-efficacy. Teachers who generate more knowledge and try to find better workable scripts for changing circumstances through engagement in self-reflective practices also strengthen their beliefs of competence to overcome future obstacles. Given that under changing circumstances, one must continuously experience small successes that add up in order to sustain levels of self-efficacy $[53,99]$, it thus seems that generating new knowledge to improve one's functioning leads to such small successes. This finding can therefore be seen as indirect evidence of the beneficial role of self-reflection in adapting teaching practices to the circumstances at hand (e.g., [31]). So, rather than that beliefs of competence motivate teachers to learn, does learning generate beliefs of competence.

Secondly, we found evidence for the assumed relationship between task interdependence and self-reflection (Hypotheses $2 \mathrm{a}$ and $2 \mathrm{~b}$ ). Teachers' perceptions of needing to interact to complete tasks positively influenced their engagement in self-reflective activities. This finding adds to the existing evidence regarding the beneficial role of collaboration for teachers' engagement in learning activities $[9,15,65,66]$. Exploration of the dynamic relations between perceived task interdependence and self-reflection pointed towards the reversed effect: Apparently, self-reflection significantly contributes to sustain teachers' perceptions of task interdependence. Together, these effects indicate that perceptions of task interdependence and engagement in self-reflection are reciprocally related. While teachers are reflecting on how to interact with team members, they discover workable scripts for possible future interactions. Thus when enacting their newly developed scripts, teacher are able to discover that team members provide them with new information, given that they perceive these interactions with team members as beneficial to complete the tasks at hand. In turn, they can then use this information to further reflect on how to improve. As such, self-reflection and perceptions of task interdependence co-develop (e.g., [24,34,100-102]). Their co-development implies that change in either one of these processes can initiate change in the other, given that there is potential to interact.

Thirdly, with respect to the relations between self-efficacy and task interdependence (Hypotheses 3a and $3 b$ ), we did not find time-based dynamic relations between task interdependence and self-efficacy, Apparently, levels of beliefs in one's own competence stem both from previous levels of those beliefs as well as from levels of engagement in self-reflection, rather than from perceptions of task interdependence. This finding contrasts with claims about the mediational role collaboration, or more generally, workplace conditions play in the relation between leadership practices and self-efficacy beliefs (e.g., $[2,10,81,84])$.

Fourthly, as assumed in hypothesis $4 \mathrm{a}$, consideration and stimulation positively influenced task interdependence: a leader who considers the needs and feelings of a teacher more, and challenges that teacher to calibrate the adequacy of knowledge more, positively influences teacher's perception of task interdependence. This suggest that when teachers feel more supported by their leader, they also feel more empowered to interact with their team members to complete tasks (e.g., [69,103,104]), validating the impact of leadership practices on collaboration, and more generally, working conditions in schools as found in previous studies [77,84]. Given the effects of task interdependence on self-reflection as found in this study, this finding substantiates claims of the indirect effect of leadership on teacher learning as mediated by teacher collaboration [2,10]. A leader who enacts, and also grows into, a transformational role is in an indirect way beneficial for teachers to become more engaged in 
self-reflection. Additionally, exploration of the opposite effect (Hypothesis 4b) gave no signs that the fit of the model could be strengthened by adding the influence from task interdependence to consideration and stimulation. This indicates that, at least within the short timeframe that we measured, collaboration on tasks does not lead to more distributed forms of leadership, nor does it offer an explanation of the increase in transformational leadership that we found. Subsequent longitudinal research using data collected over a longer period of time might capture such processes better.

In sum, our longitudinal study provides some strong evidence for causality and time-based dynamic relations. The findings contradict the central role of self-efficacy in elevating teacher engagement in learning activities $[9,79]$. It did however corroborate the initiating role of transformational leadership practices $[71,74]$ in affecting teacher collaboration. More specifically, its increase helped to sustain levels of task interdependence. Additionally, we were able to provide some initial evidence for the reciprocity between task interdependence and self-reflection in sustaining each other on the one hand, and the subsequent positive influence of self-reflection on sustaining levels of self-efficacy on the other hand. This provides some evidence for the beneficial role of working in teams to foster teacher learning, and shows that, after teams have been formed, teachers' engagement in knowledge generating activities helps to sustain their perceptions of being interdependent to complete tasks successfully. This suggests that teachers co-create their own learning environment through collaboration and engagement in reflective learning, while being supported by a considerate and stimulating leader. Important to note, this investigation does not only provide evidence for the fact that variables are causally related, but it sheds some light on how variables are related, as the multivariate LDS model allows tracking the mutual influences of the variables from occasion to occasion. In our opinion, this is only an intermediate step in moving from understanding which variables cause change in, ultimately, teaching practices and student learning, to understanding how changing organizational and psychological factors interact to build school-wide capacity for sustained improvement $[5,49]$.

\section{Limitations}

In this study we made use of a versatile model type for longitudinal data: the Latent Difference Score model [20]. It allowed to model change in a way similar to latent growth curve models but extended on them by adding proportional change to constant change. Change is thereby defined in a precise way, which makes interpretations of influences on change more robust.

Despite this benefit, a model without constant change factors fitted better to the data than a model with constant change factors. Given the high initial means of task interdependence, self-efficacy, and self-reflection, little systematic constant positive change might have been expected after the first measurement occasion. That is, finding growth of these variables may have been hindered by a ceiling effect. This issue might be resolved by using different instruments, such as 7-point questionnaires that can capture more variation. However, measurement instruments may not be the main problem. The little systematic constant change found may also be explained by the differences in the frames of reference respondents may have when answering the questionnaires, resulting in "response shift". [105]. With response shift, observed changes in respondents' test scores at different measurement occasions may reflect something other than true changes in the attributes that we want to measure. Over a period of time teachers may have changed their internal standards or redefined their targets. For example, VET 
teachers may become more critical about team work, their own competence and their motivation to learn, due to institutional policy (formation of multidisciplinary teams) and the social settings in which they are embedded. The measurement of changed teachers' perceptions of task interdependence, their self-efficacy beliefs and engagement in self-reflective learning activities can bring about the additional problem that teachers may also change their frame of reference, rendering scores from different measurement occasions incomparable. On the other hand, it also may be that these variables are already beneficial for teachers' improvements when they remain constant. For instance, self-reflection stimulates teachers to remain proficient employees, now and in the future. Whereas professional learning is a core competence of teachers, their productivity lies at the knowledge and skills they can teach their pupils (e.g., [50]). Moreover, most of the participants had many years of service, and seem to experience a high level of competence in their profession. For experienced teachers sustaining high levels of self-reflection may be important for adapting effectively to the (changing) circumstances at hand. Their development, in this sense, would be similar to the innovation of new services as found in other organizations and industries [25]. Future research must establish whether a sustained level of self-reflection can continuously generate solutions to challenges at the moments the challenges present themselves.

A second caution for interpreting our findings, however, is the fit of the model to the data. Although the RMSEA value was good and the SRMR value was acceptable, the CFI value indicated a weak fit [95]. Although this could at first sight leave some concerns about whether other types of models may fit the data better, such as more simple cross-lagged models [18], the inclusion of latent difference factor means allowed us to assess whether, and when, any change occurred. Moreover, a series of $\Delta \chi^{2}$ tests indicated that the parsimonious multivariate proportional change model fitted the data best, and that none of the variables was spurious. An additional analytic caution for interpreting our findings is that data were collected from teachers who were nested in teams. We were unable to correct for this dependency in the data, because we did not have enough power to do so: the amount of parameters vastly exceeded the amount of teams. Future research must establish to what extent being a member of a team affects the coupling of reflective activities to and from other variables.

Lastly, despite the benefits of a longitudinal design, inferring causality must still be done with caution, as unmeasured variables may account for the found effects better than the measured variables $[18,20]$. Although we used variables which were shown to be important to elevate self-reflection, we used only a small set of variables that make up a school's capacity for change (i.e., teachers' learning activities, personal and structural resources, and directive influences such as leadership). Additionally, self-reflection's initial level and changes were not fully explained by the variables in the model. Inclusion of variables tapping into such concepts as the sharing of information, teacher commitment, functional team conflict, distributed leadership practices, and shared focus on teacher learning, would validate and expand our findings [29,31,106-109]. Investigating whether these relations also hold over time using data gathered from principals and students, or in other organizations or industries, would be a fruitful endeavor for future research (e.g., [110]). 


\section{Conclusions}

All in all, an image rises from this longitudinal study that, in a Dutch VET context, educational improvements are driven by the reciprocity between self-reflective activities and perceptions of task interdependence. Interacting with team members to complete tasks provides input for teachers' reflections about one's functioning, which in turn provide input for subsequent interactions, and so on. Sustained engagement in self-reflection then results in sustained beliefs in self-efficacy, which suggests that the reciprocity between interaction and reflection can thus continuously offer teachers mastery experiences. Finally, a considerate and stimulating transformational leader can furthermore facilitate this process. Together, the present findings point to the important role transformational leadership practices play in facilitating teamwork and sustaining teachers' levels of reflection.

\section{Acknowledgments}

The authors would like to thank Barbara Müller for her invaluable advice in the preparation of the manuscript. This work was supported by the NWO Programming Council for Educational Research (PROO) [grant number 411-07-302].

\section{Author Contributions}

All authors accept responsibility for the contents of the manuscript and agree on the order of the authorship. A.O.G.B. collected the data, conducted the analyses, wrote the first draft and processed changes to the manuscript. P.S. conceived of the study, participated in its design, made improvements to the manuscript and finalized it. M.E. helped to draft the manuscript, and suggested and made improvements to the manuscript. K.v.V. co-conceived of the study and also suggested improvements.

\section{Appendixes}

Appendix 1. Response rates per occasion.

\begin{tabular}{cccc}
\hline Questionnaires: & $\mathrm{t} 1$ & $\mathrm{t} 2$ & $\mathrm{t} 3$ \\
Send & 853 & 857 & 822 \\
Returned & 454 & 449 & 389 \\
Response rate & $53 \%$ & $52 \%$ & $47 \%$ \\
Dropped & -16 & -87 & -65 \\
Unique responses on measurement occasions & & & \\
Occasions 1 and 2 and 3 & 82 & 45 & 54 \\
Occasions 1 and 2 or 1 and 3 or 2 and 3 & 167 & 82 & 81 \\
Occasion 1 or 2 or 3 & & 655 & \\
Total unique responses in the data set & & \\
\hline
\end{tabular}

Note: cases could be dropped, for instance, because not all returned questionnaires were filled out completely. 
Appendix 2. Sample descriptives per occasion.

\begin{tabular}{ccccc}
\hline & & $\mathbf{t 1}$ & $\mathbf{t 2}$ & $\mathbf{t 3}$ \\
\hline gender (men) & & $66 \%$ & $68 \%$ & $60 \%$ \\
age (years) & mean & 48 & 48 & 48 \\
& $\mathrm{sd}$ & 9 & 10 & 10 \\
& $\min$ & 22 & 20 & 21 \\
Job size & $\max$ & 62 & 63 & 65 \\
Tenure & $>32 \mathrm{~h}$ & $61 \%$ & $62 \%$ & $58 \%$ \\
& $>20$ years & $33 \%$ & $32 \%$ & $32 \%$ \\
Education & 10 years & $20 \%$ & $22 \%$ & $22 \%$ \\
& $<1 / 2$ year & $4 \%$ & $2 \%$ & $0 \%$ \\
& Master & $16 \%$ & $16 \%$ & $14 \%$ \\
& Bachelor & $72 \%$ & $74 \%$ & $79 \%$ \\
& 2nd education & $12 \%$ & $10 \%$ & $7 \%$ \\
\hline
\end{tabular}

Note: Years and percentages have been rounded.

Appendix 3. Variables and their scales.

All scales were responded to as follows: (1) disagree much, (2) partially disagree, (3) do not disagree, do not agree, (4) partially agree, (5) agree much.

\section{Transformational Leadership: Individual Consideration and Intellectual Stimulation}

Includes attending to the needs and feelings of individual teachers, support of professional development of teachers and challenging teachers to constantly evaluate their current knowledge and daily practices $[2,10,12]$.

\begin{tabular}{|c|c|c|c|c|}
\hline \multirow[t]{2}{*}{ My Leader } & \multirow{2}{*}{$\begin{array}{l}\text { Invariant } \\
\text { Factor } \\
\text { Loadings }\end{array}$} & \multicolumn{3}{|c|}{ Residual Variances } \\
\hline & & t1 & t2 & t3 \\
\hline takes the opinions of individual teachers seriously & 1.000 & 0.507 & 0.325 & 0.418 \\
\hline shows appreciation when a teacher takes the initiative for educational improvement & 0.998 & 0.443 & 0.386 & 0.436 \\
\hline listens carefully to the ideas of team members & 0.955 & 0.434 & 0.362 & 0.383 \\
\hline has an eye and an ear for problems being experienced by teachers with policy implementation & 0.930 & 0.387 & 0.349 & 0.325 \\
\hline helps teachers to express their emotions & 0.839 & 0.548 & 0.475 & 0.542 \\
\hline encourages teachers to try new things in line with their own interests & 0.940 & 0.335 & 0.369 & 0.332 \\
\hline stimulates teachers to reflect on how to improve in the department & 0.949 & 0.298 & 0.328 & 0.275 \\
\hline $\begin{array}{l}\text { encourages teachers to seek and discuss new information and } \\
\text { ideas which are relevant to the direction in which the department is developing }\end{array}$ & 0.914 & 0.303 & 0.279 & 0.321 \\
\hline engages individual teachers in discussion of personal and professional goals & 0.847 & 0.325 & 0.331 & 0.393 \\
\hline encourages teachers to experiment with new teaching methods & 0.833 & 0.532 & 0.596 & 0.614 \\
\hline creates sufficient opportunities for teachers to work on their professional development & 0.913 & 0.646 & 0.474 & 0.545 \\
\hline
\end{tabular}


Appendix 3. Cont.

\section{Task Interdependence}

Refers to the degree to which interaction and coordination of team members are required to complete tasks $[9,12,55]$.

\begin{tabular}{ccc}
\hline & $\begin{array}{c}\text { Invariant } \\
\text { Factor } \\
\text { Loadings }\end{array}$ & $\begin{array}{c}\text { Invariant } \\
\text { Residual } \\
\text { Variances }\end{array}$ \\
\hline For the conduct of our jobs, the members of my team need information from each other & 1.000 & 0.128 \\
To do our jobs well, we have to work together as a team & 1.012 & 0.087 \\
The work of one team member influences the conduct of the tasks of other team members & 0.880 & 0.623 \\
To do our work well, we have to coordinate our work as a team & 0.987 & 0.169 \\
\hline
\end{tabular}

Cronbach's alphas are at: $\mathrm{t} 1=0.783 ; \mathrm{t} 2=0.779 ; \mathrm{t} 3=823$.

\section{Occupational Self-Efficacy}

A future-oriented belief about the level of competence person expects to display in a given situation $[9,12,55,90]$.

\begin{tabular}{ccccc}
\hline & Invariant & \multicolumn{2}{c}{ Residual Variances } \\
\cline { 4 - 6 } & $\begin{array}{c}\text { Factor } \\
\text { Loadings }\end{array}$ & t1 & t2 & t3 \\
\hline $\begin{array}{c}\text { I can remain calm when confronted with difficulties in } \\
\text { my work because I know that I can fall back on my competences }\end{array}$ & 1.000 & 0.421 & 0.363 & 0.299 \\
\hline When I am confronted with a problem in my work, & 0.999 & 0.352 & 0.242 & 0.243 \\
\hline $\begin{array}{c}\text { I can usually find different solutions } \\
\text { Whatever happens in my work, I can usually manage }\end{array}$ & 1.005 & 0.277 & 0.292 & 0.220 \\
\hline My past experiences have prepared me well for my current work & 1.024 & 0.411 & 0.315 & 0.391 \\
\hline In my work, I achieve the goals which I have set for myself & 0.937 & 0.413 & 0.321 & 0.283 \\
\hline I am adequately equipped to face the demands of my work & 0.966 & 0.330 & 0.287 & 0.265 \\
\hline
\end{tabular}

Cronbach's alphas are at: $\mathrm{t} 1=0.801 ; \mathrm{t} 2=0.800 ; \mathrm{t} 3=0.850$.

\section{Reflection}

An individual learning activity aimed at making implicit knowledge explicit $[9,12,42,55]$.

\begin{tabular}{|c|c|c|c|c|}
\hline & \multirow{2}{*}{$\begin{array}{c}\text { Invariant } \\
\text { Factor } \\
\text { Loadings } \\
\end{array}$} & \multicolumn{3}{|c|}{ Residual Variances } \\
\hline & & $\mathbf{t 1}$ & $\mathbf{t} 2$ & t3 \\
\hline I ponder what I find important in my work & 1.000 & 0.140 & 0.181 & 0.141 \\
\hline I monitor progress with regard to the goals of my work & 0.935 & 0.255 & 0.210 & 0.219 \\
\hline I reflect on the manner in which I do my work & 0.985 & 0.147 & 0.197 & 0.180 \\
\hline I compare my performance with how I performed one year ago & 0.921 & 0.526 & 0501 & 0.425 \\
\hline I think about my communication with colleagues & 0.976 & 0.277 & 0.256 & 0.212 \\
\hline
\end{tabular}

Cronbach's alphas are at: $\mathrm{t} 1=0.823 ; \mathrm{t} 2=0.815 ; \mathrm{t} 3=0.854$. 
Appendix 4. Chi-square difference $\left(\Delta \chi^{2}\right)$ tests of invariance and stability.

\begin{tabular}{lllccc}
\hline & & TLcs & Task & SE & Refl \\
\hline factor loadings $\lambda$ 's & equal-unequal & $24.143(20)$ & $8.061(6)$ & $9.658(10)$ & $4.758(8)$ \\
residual variances $\psi$ 's & equal-unequal & $36.889(22)^{\dagger}$ & $4.380(8)$ & $55.265(12) *$ & $23.961(10) *$ \\
autoregressions $\beta$ 's & absent-free & $183.144(2) *$ & $88.125(2) *$ & $154.481(2) *$ & $163.616(2) *$ \\
\hline$* p<0.01,{ }^{\dagger} p<0.05$, degrees of freedom $(d f)$ in parentheses, TLcs = transformational leadership consideration \\
and stimulation; task = task interdependence; SE = self-efficacy; Refl = self-reflection, $\Delta \chi^{2}$ tests of the \\
autoregressions include the assumption of measurement error with a mean of 0, and TLcs, SE, and Refl had \\
variant residual variances, Task had invariant residual variance, A significant $\Delta \chi^{2}$ test indicates a worsening \\
through restraint. The more restraint model is listed first in the second column. Thus, significance indicates to \\
select the second listed model, and vice versa.
\end{tabular}

Appendix 5. Correlation Table.

Means, Standard Errors of the means, and Correlations from the measurement model.

\begin{tabular}{|c|c|c|c|c|c|c|c|c|c|c|c|c|c|}
\hline Variables & Mean & S.E. & 1 & 2 & 3 & 4 & 5 & 6 & 7 & 8 & 9 & 10 & 11 \\
\hline 1. TLcs [1] & 3.680 & 0.051 & & & & & & & & & & & \\
\hline 2. TLcs [2] & 3.804 & 0.047 & $0.415 *$ & & & & & & & & & & \\
\hline 3. TLcs [3] & 3.884 & 0.048 & $0.471 *$ & $.574 *$ & & & & & & & & & \\
\hline 4. Task [1] & 4.556 & 0.027 & $0.116^{*}$ & $0.064 \dagger$ & 0.034 & & & & & & & & \\
\hline 5. Task [2] & 4.505 & 0.029 & 0.107 * & $0.113 *$ & $0.083^{*}$ & $0.113 *$ & & & & & & & \\
\hline 6. Task [3] & 4.467 & 0.032 & 0.118 * & $0.106 *$ & $0.106^{*}$ & $0.100 *$ & $0.139 *$ & & & & & & \\
\hline 7. SE [1] & 4.088 & 0.031 & $0.115 *$ & 0.002 & 0.034 & $0.085 *$ & $0.059 *$ & $0.060 *$ & & & & & \\
\hline 8. SE [2] & 4.147 & 0.030 & $0.071^{\dagger}$ & 0.032 & 0.004 & $0.046 *$ & $0.080 *$ & 0.026 & $0.164 *$ & & & & \\
\hline 9. SE [3] & 4.126 & 0.034 & 0.076 & 0.032 & 0.037 & -0.025 & $0.053 *$ & $0.047^{\dagger}$ & $0.132 *$ & $0.155 *$ & & & \\
\hline 10. Refl [1] & 4.350 & 0.026 & 0.049 & 0.055 & 0.015 & $0.094 *$ & $0.080 *$ & $0.046^{\dagger}$ & $0.116^{*}$ & $0.080 *$ & $0.056 *$ & & \\
\hline 11. Refl [2] & 4.271 & 0.029 & 0.055 & $0.067 *$ & 0.055 & 0.080 & 0.111 & $0.047^{\dagger}$ & $0.072 *$ & 0.109 * & $0.078 *$ & 0.140 * & \\
\hline 12. Refl [3] & 4.261 & 0.030 & $0.132 *$ & $0.108 *$ & $0.097 *$ & $0.091 *$ & $0.092 *$ & $0.105 *$ & $0.112 *$ & $0.084 *$ & $0.100 *$ & $0.151 *$ & $0.188 *$ \\
\hline
\end{tabular}

${ }^{*} p<0.01,{ }^{\dagger} p<0.05 ; \mathrm{TLcs}=$ Transformational Leadership consideration and stimulation; Task $=$ task interdependence; SE = self-efficacy;

Refl = self-reflection; [1], [2], [3] indicate measurement occasions 1, 2, 3, respectively. 
Appendix 6. Latent Difference Score models.

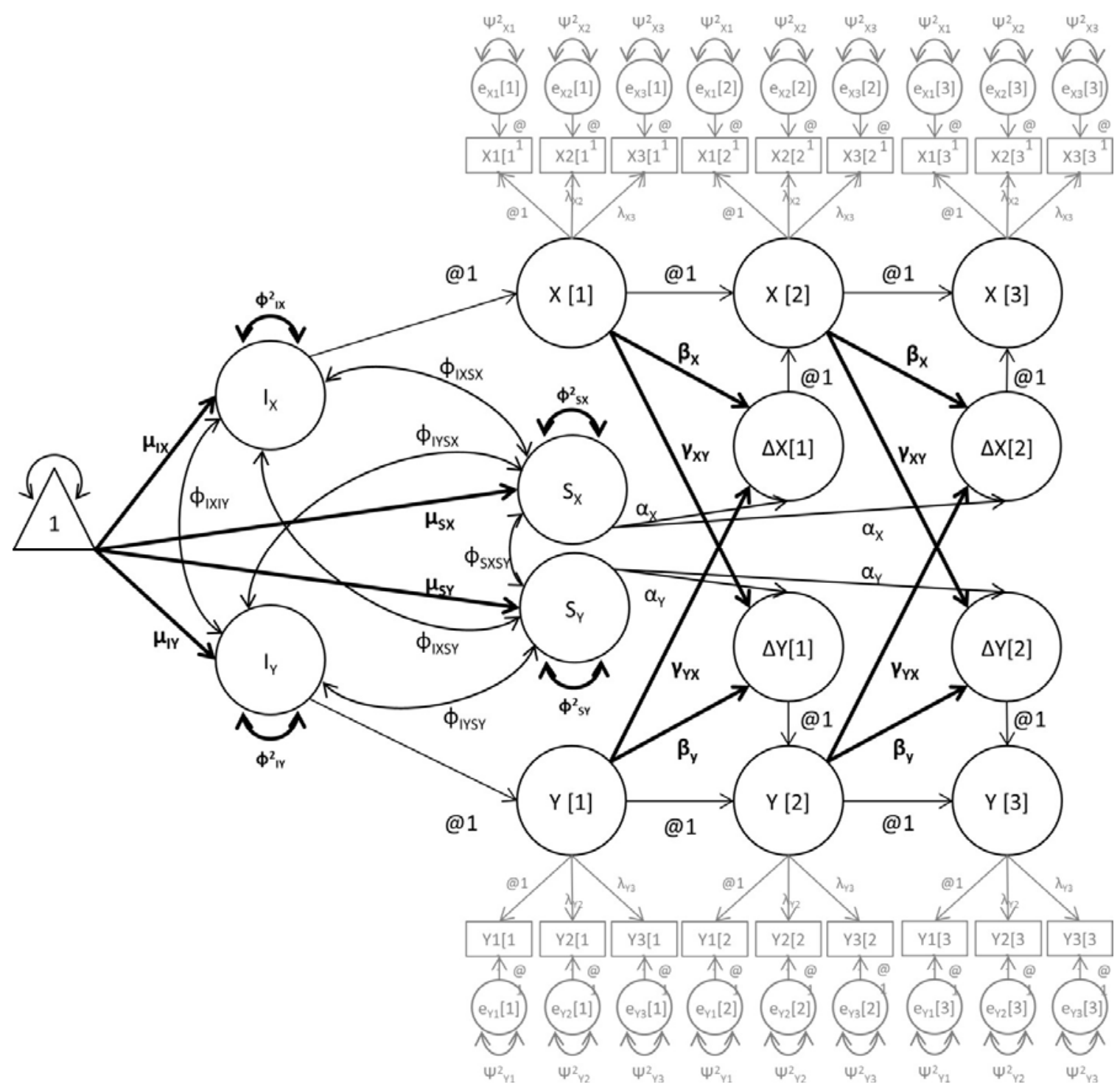

Bivariate dual change Latent Difference Score model. This model may appear complicated, but because a number of constraints are typically applied there are few parameters that are estimated. Roughly from middle left to bottom right: Bold and grey are used to create contrast to make the graph easier to read. The triangle represents a constant with a mean of 1 and variance of 1 , circles represent factors, squares represent observations. $\mathrm{Y}$ and $\mathrm{X}$ represent variables. I represents an initial factor with a mean $\mu_{\mathrm{I}}$ and variance $\phi_{\mathrm{I}}{ }^{2}$. S stands for slope and represents a systematic constant change factor (or intra-individual constant growth), also with a mean and variance. $\phi$ 's represent co-variances between initial and slope factors. $\Delta$ stands for difference. [1-3] indicate measurement occasions. $\Delta Y[1]$ represents thus the first latent difference score of variable $\mathrm{Y}$, and is the most important parameter; hence the name of the model. It represents intra-individual change proportional to the levels of its influences on the previous time point. The $\Delta$ values are a function of slope factor loadings ( $\alpha$ 's), autoregressive effects $(\beta$ 's), and regressions on other variables ( $\gamma$ 's, or couplings). $\alpha$ 's are typically set at one when measurement occasions are equidistant. The values of $\Delta$ 's may differ over time, even when their influences are invariant (which they are in the figure, which is indicated by equal labels). They are created from measurement occasion factors (e.g., Y[2]), by fixing their factor loading at one (@1). 
Furthermore, Y[1] represents the factor of measurement occasion 1 of variable Y, Y1[1] represents the first item of variable $\mathrm{Y}$ on the first measurement occasion, $\mathrm{e}_{\mathrm{y} 1}[1]$ represent the measurement error of the first item, and $\psi^{2}$ is its variance. Measurement occasion factor loadings ( $\lambda$ 's) must be held invariant. Measurement error variance can be held invariant (and it is in the figure). The model in the figure is termed a dual change model because change stems from both a constant change factor (S), and autoregressions ( $\beta$ 's). The model can be changed into a constant change model by fixing the autoregressions at zero, and into a proportional change model by removing the slope factor and freeing the autoregressions.

Appendix 7. Model selection and optimization Chi-square difference $\left(\Delta \chi^{2}\right)$ tests.

\begin{tabular}{lccccc}
\hline & & TLCs & Task & SE & Refl \\
\hline Change model & dual-proportional & $461.382(2) *$ & $269.723(2) *$ & $71.610(2) *$ & $109.127(2) *$ \\
Change model & constant_dual & $348.621(1) *$ & $1.351(1)$ & $2.249(1)$ & $17.969(1) *$ \\
Change model & constant_proportional & $810.003(3) *$ & $271.074(3) *$ & $73.859(3) *$ & $127.096(3) *$ \\
\hline Proportional change model optimization & $20.688(1) *$ & $0.606(1)$ & $1.123(1)$ & $2.026(1)$ \\
autoregressions $\beta$ 's equal-unequal & & & & \\
\hline
\end{tabular}

$* p<0.01$, degrees of freedom (df) in parentheses, TLcs $=$ transformational leadership consideration and stimulation; task = task interdependence; SE = self-efficacy; Refl = self-reflection, TLcs, SE, and Refl had variant residual variances, Task had invariant residual variance. A significant $\Delta \chi^{2}$ test indicates a worsening through restraint. The more restraint model is listed first in the second column. Thus, significance indicates to select the second listed model, and vice versa.

Appendix 8. Univariate latent proportional change models, their trajectories, and their fit measures.

\section{Transformational leadership: individual consideration and intellectual stimulation}

(A) Latent proportional change model

(B) Trajectories of 4 participants
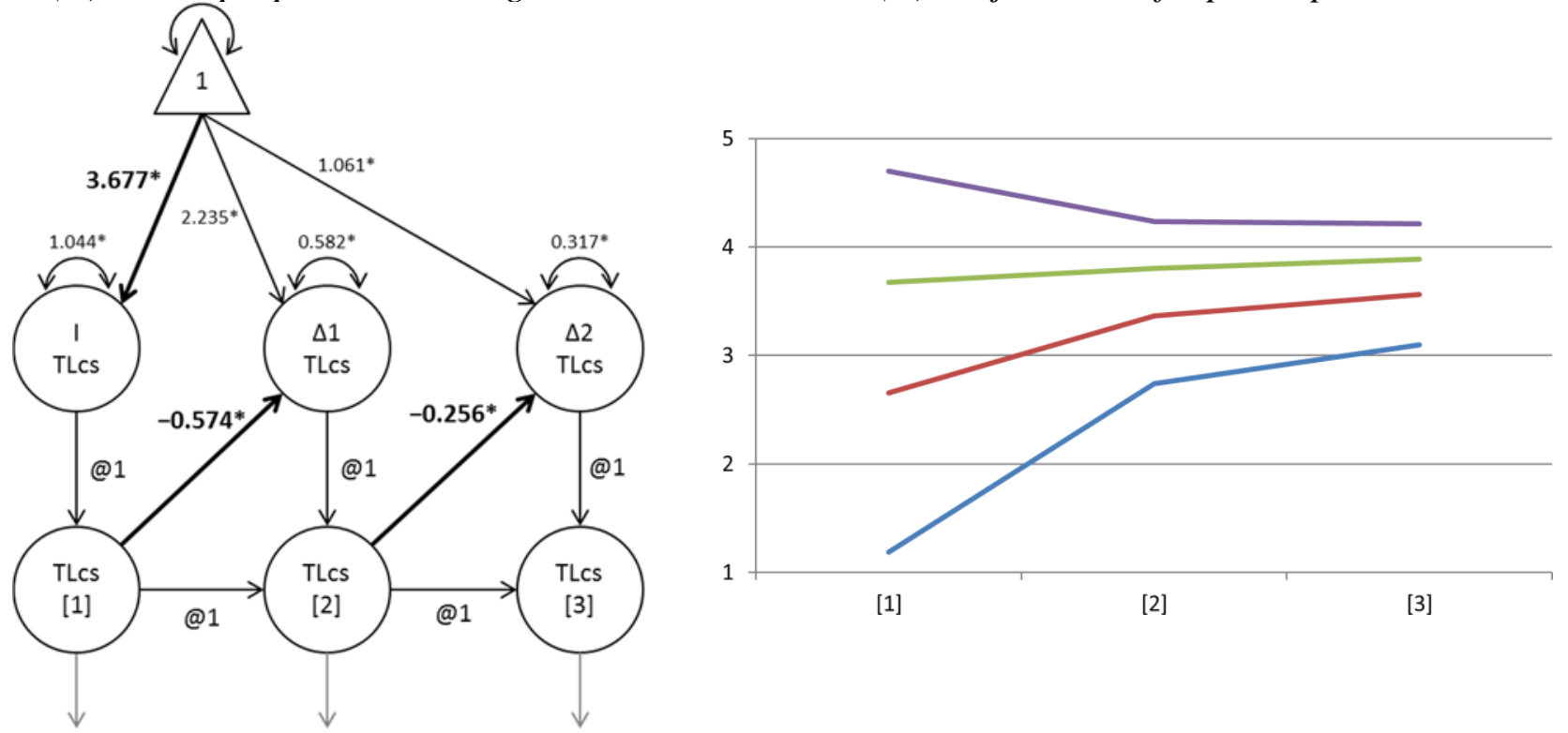

Fit. Measures: $\chi^{2}(d f)=2087.860(543) *, \mathrm{RMSEA}=0.066, \mathrm{CFI}=0.859, \mathrm{SRMR}=0.082$. 
Appendix 8. Cont.

Task interdependence

(A) Latent proportional change model

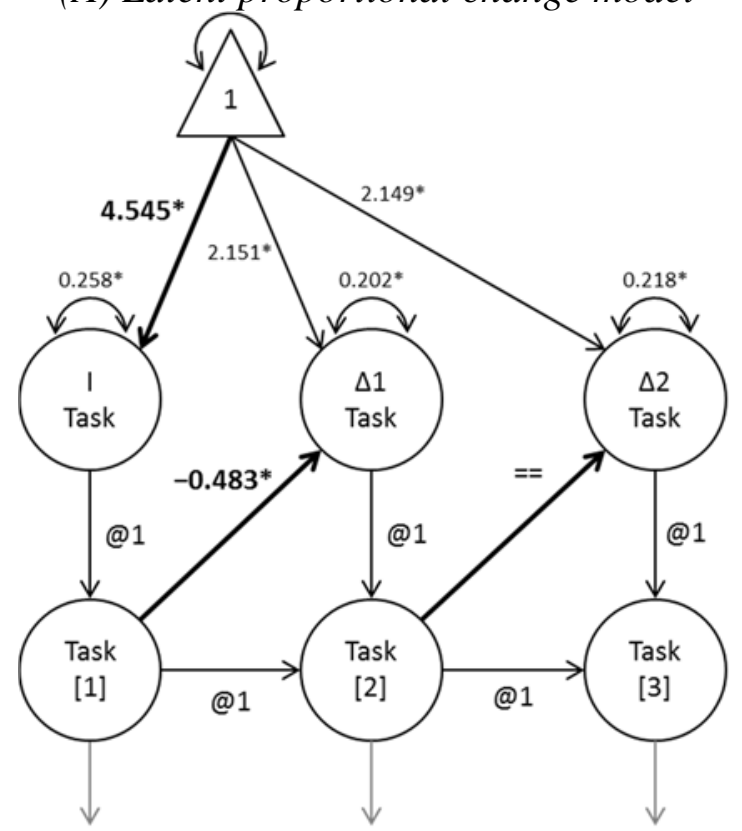

(B) Trajectories of 4 participants

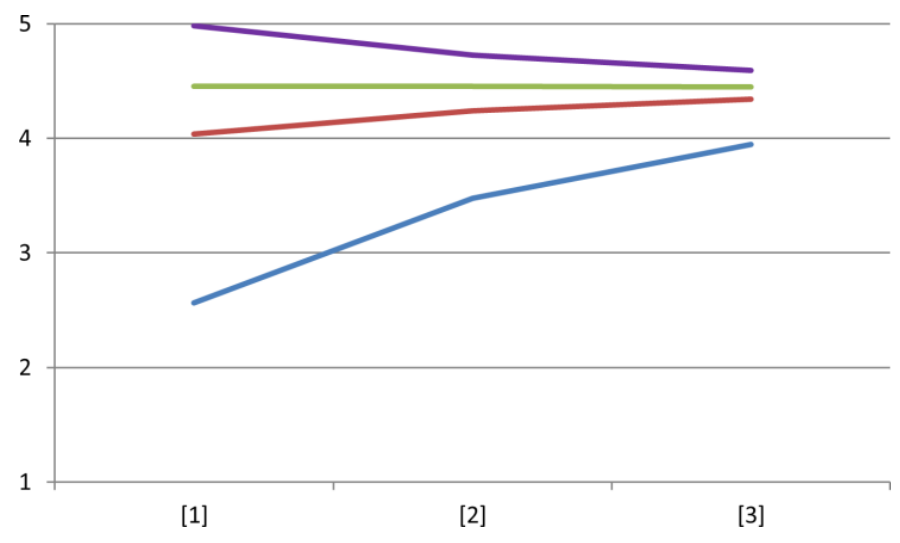

Fit. Measures: $\chi^{2}(d f)=205.247(76) *$, RMSEA $=0.051, \mathrm{CFI}=0.983, \mathrm{SRMR}=0.104$.

\section{Self-efficacy}

(A) Latent proportional change model

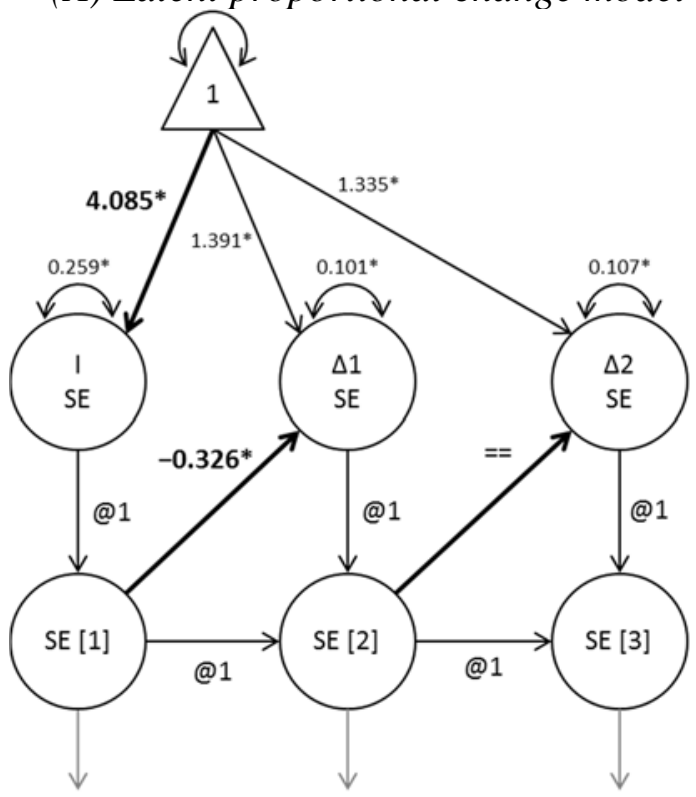

(B) Trajectories of 4 participants

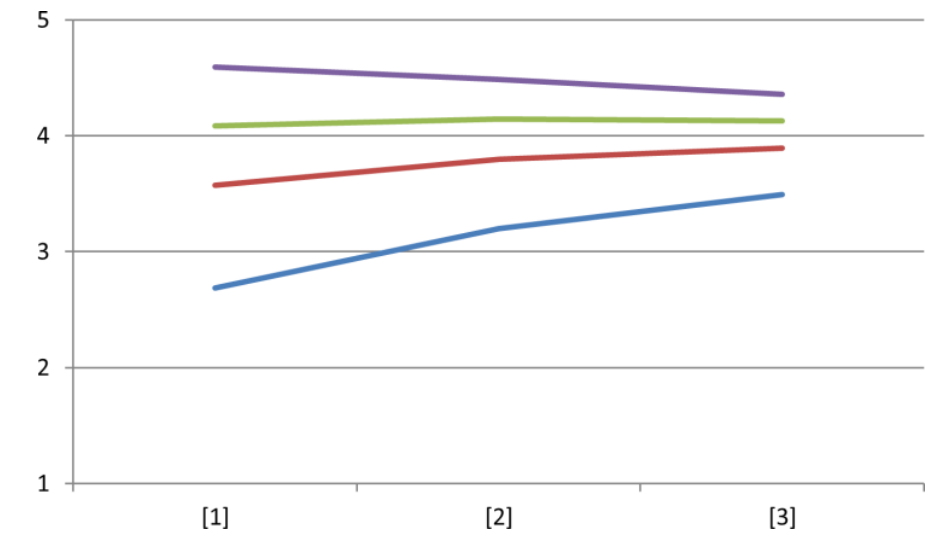

Fit. Measures: $\chi^{2}(d f)=508.794(159) *, \mathrm{RMSEA}=0.058, \mathrm{CFI}=0.852, \mathrm{SRMR}=0.119$. 
Appendix 8. Cont.

\section{Self-reflection}

(A) Latent proportional change model

(B) Trajectories of 4 participants
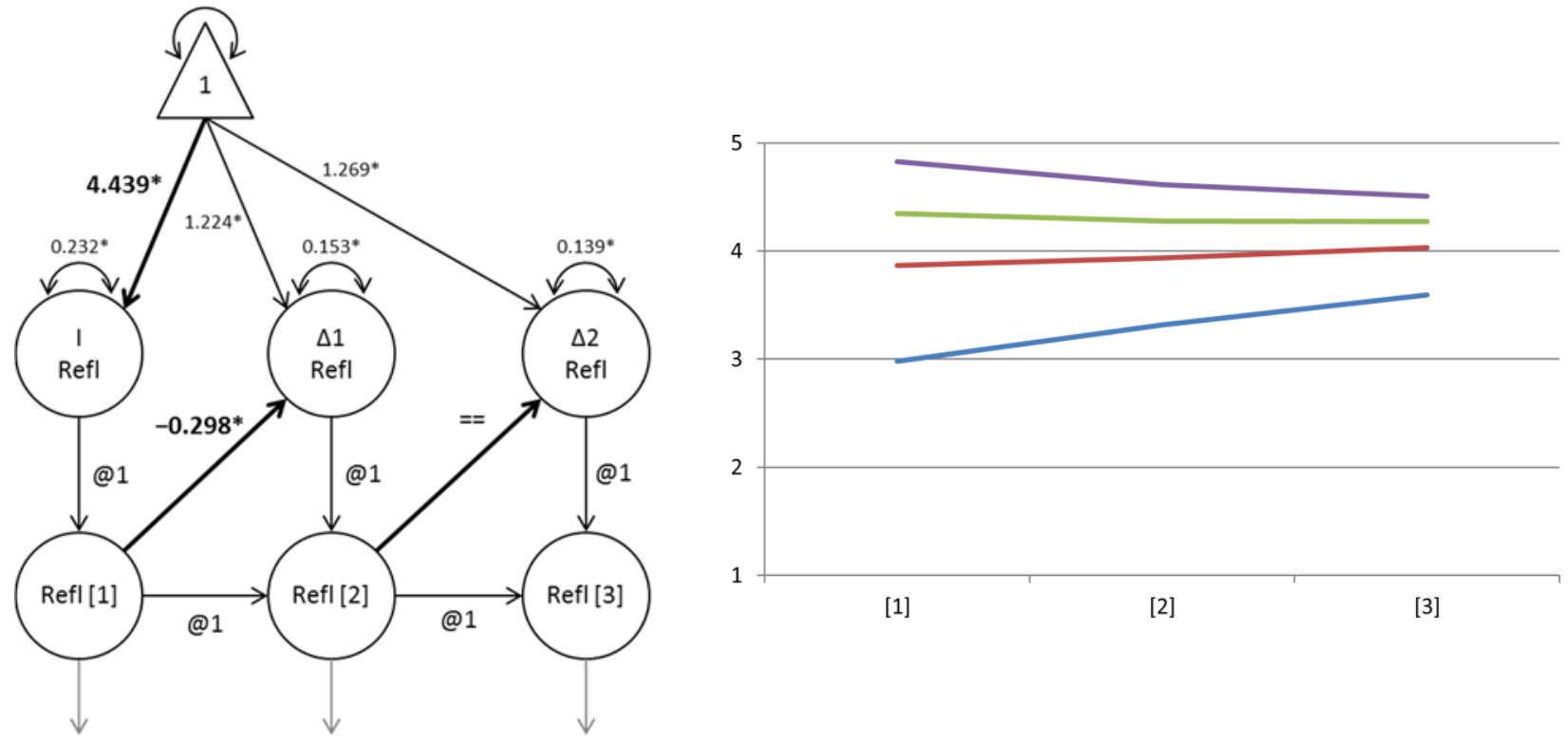

Fit. Measures: $\chi^{2}(d f)=329.371(109) *, \mathrm{RMSEA}=0.056, \mathrm{CFI}=0.906, \mathrm{SRMR}=0.125$.

$* p<0.01$ (A)'s: Double equality signs indicate that this parameter is contraint to be equal over time; Observations, measurement occasion factor loadings, and measurement errors are not shown, but their inclusion is referred to by the gray arrows; (B)'s: Trajectories per variable are based on model estimated values, derived from initial values of 4 randomly selected participants.

\section{Conflicts of Interest}

The authors declare no conflict of interest.

\section{References}

1. Clarke, D.J.; Hollingsworth, H. Elaborating a model of teacher professional growth. Teach. Teach. Educ. 2002, 18, 947-967.

2. Geijsel, F.P.; Sleegers, P.J.; Stoel, R.D.; Kruger, M.L. The effect of teacher psychological and school organizational and leadership factors on teachers' professional learning in Dutch schools. Elem. Sch. J. 2009, 109, 1-22.

3. Sleegers, P.; Bolhuis, S.; Geijsel, F. School Improvement within a Knowledge Economy: Fostering Professional Learning from a Multidimensional Perspective. In International Handbook of Educational Policy; Cumming, B., Livingstone, D.L., Eds.; Kluwer: Dordrecht, The Netherlands, 2005; pp. 527-543.

4. Stoll, L. Capacity building for school improvement or creating capacity for learning? A changing landscape. J. Educ. Chang. 2009, 10, 115-127.

5. Stoll, L.; Bolam, R.; McMahon, A.; Wallace, M.; Thomas, S. Professional learning communities: A review of the literature. J. Educ. Chang. 2009, 7, 221-258. 
6. Richardson, V.; Placier, P. Teacher Change. In Handbook of Research on Teaching; American Educational Research Association: Washington, DC, USA, 2001; pp. 905-947.

7. Kwakman, K. Factors affecting teachers' participation in professional learning activities. Teach. Teach. Educ. 2003, 19, 149-170.

8. Smylie, M.A.; Lazarus, V.; Brownlee-Conyers, J. Instructional outcomes of school-based participative decision making. Educ. Eval. Policy Anal. 1996, 18, 181-198.

9. Runhaar, P.; Sanders, K.; Yang, H. Stimulating teachers' reflection and feedback asking: An interplay of self-efficacy, learning goal orientation, and transformational leadership. Teach. Teach. Educ. 2010, 26, 1154-1161.

10. Thoonen, E.E.J.; Sleegers, P.J.C.; Oort, F.J.; Peetsma, T.T.D.; Geijsel, F.P. How to improve teaching practices: The role of teacher motivation, organizational factors, and leadership practices. Educ. Adm. Q. 2011, 47, 496-536.

11. Van Woerkom, M. The concept of critical reflection and its implications for human resource development. Adv. Dev. Hum. Resour. 2004, 6, 178-192.

12. Oude Groote Beverborg, A.; Sleegers, P.J.C.; van Veen, K. Fostering teacher learning in VET colleges: Do leadership and teamwork matter? Teach. Teach. Educ. 2015, 48, 22-33.

13. Desimone, L.M. Improving impact studies of teachers' professional development: Toward better conceptualizations and measures. Educ. Res. 2009, 38, 181-199.

14. Garet, M.S.; Porter, A.C.; Desimone, L.; Birman, B.F.; Yoon, K.S. What makes professional development effective? Results from a national sample of teachers. Am. Educ. Res. J. 2001, 38, 915-945.

15. Sleegers, P.J.C.; Thoonen, E.E.J.; Oort, F.J.; Peetsma, T.T.D. Improving classroom practices: The role of school-wide capacity for sustainable improvement. J. Educ. Adm. 2014, 52, 617-652.

16. Vescio, V.; Ross, D.; Adams, A. A review of research on the impact of professional learning communities on teaching practice and student learning. Teach. Teach. Educ. 2008, 24, 80-91.

17. Cole, D.A.; Maxwell, S.E. Testing mediational models with longitudinal data: Questions and tips in the use of structural equation modeling. J. Abnorm. Psychol. 2003, 112, 558-577.

18. Eschleman, K.J.; LaHuis, D. Advancing occupational stress and health research and interventions using latent difference score modelling. Int. J. Stress Manag. 2013, 21, 112-136.

19. Maxwell, S.E.; Cole, D.A.; Mitchell, M.A. Bias in cross-sectional analyses of longitudinal mediation: Partial and complete mediation under an autoregressive model. Multivar. Behav. Res. 2011, 46, 816-841.

20. McArdle, J.J. Latent variable modeling of differences and changes with longitudinal data. Annu. Rev. Psychol. 2009, 60, 577-605.

21. Heck, R.H.; Hallinger, P. Collaborative leadership effects on school improvement: Integrating unidirectional-and reciprocal-effects models. Elem. Sch. J. 2010, 111, 226-252.

22. Salanova, M.; Bakker, A.B.; Llorens, S. Flow at work: Evidence for an upward spiral of personal and organizational resources. J. Happiness Stud. 2006, 7, 1-22.

23. Xanthopoulou, D.; Bakker, A.B.; Demerouti, E.; Schaufeli, W.B. Reciprocal relationships between job resources, personal resources, and work engagement. J. Vocat. Behav. 2009, 74, 235-244. 
24. Horn, I.S.; Little, J.W. Attending to problems of practice: Routines and resources for professional learning in teachers' workplace interactions. Am. Educ. Res. J. 2010, 47, 181-217.

25. Nonaka, I. A dynamic theory of organizational knowledge creation. Organ. Sci. 1994, 5, 14-37.

26. Spillane, J.P.; Reiser, B.J.; Reimer, T. Policy implementation and cognition: Reframing and refocussing implementation research. Rev. Educ. Res. 2002, 72, 387-431.

27. Ferrer, E.; McArdle, J.J. Longitudinal modeling of developmental changes in psychological research. Curr. Dir. Psychol. Sci. 2010, 19, 149-154.

28. Feldhoff, T.; Radisch, F.; Klieme, E. Methods in longitudinal school improvement: State of the art. J. Educ. Adm. 2014, 52, 565-736.

29. Hallinger, P.; Heck, R. Exploring the journey of school improvement: Classifying and analyzing patterns of change in school improvement processes and learning outcomes. Sch. Eff. Sch. Improv. 2011, 22, 149-173.

30. Heck, R.H.; Hallinger, P. Modelling the longitudinal effects of school leadership on teaching and learning. J. Educ. Adm. 2014, 52, 653-681.

31. Thoonen, E.E.; Sleegers, P.J.; Oort, F.J.; Peetsma, T.T. Building school-wide capacity for improvement: the role of leadership, school organizational conditions, and teacher factors. Sch. Eff. Sch. Improv. 2012, 23, 441-460.

32. Leithwood, K.; Jantzi, D.; Mascall, B. A framework for research on large-scale reform. J. Educ. Chang. 2002, 3, 7-33.

33. Poortman, C.L. Workplace Learning Processes in Senior Secondary Vocational Education. Ph.D. Thesis, University of Twente, Enschede, The Netherlands, 2007. Available online: http://doc.utwente.nl/57877/1/thesis_Poortman.pdf (accessed on 1 March 2009).

34. Truijen, K. Teacher Teaming: Exploring Factors that Influence Effective Team Functioning in a Vocational Education context. Ph.D. Thesis, University of Twente, Enschede, The Netherlands, 2012. Available online: http://doc.utwente.nl/80028/1/thesis_K_Truijen.pdf (accessed on 25 September 2013).

35. Jarvis, P. Adult Learning in the Social Context; Croom Helm: London, UK, 1987.

36. Marsick, V.J.; Watkins, K. Informal and Incidental Learning in the Workplace; Routledge: New York, NY, USA, 1990.

37. Putnam, R.T.; Borko, H. What do new views of knowledge and thinking have to say about research on teacher learning? Educ. Res. 2000, 29, 4-15.

38. Smylie, M.A.; Hart, A.W. School leadership for teacher learning and change: A human and social capital development perspective. Handb. Res. Educ. Adm. 1999, 2, 421-441.

39. Meirink, J.A.; Meijer, P.C.; Verloop, N.; Bergen, T.C. How do teachers learn in the workplace? An examination of teacher learning activities. Eur. J. Teach. Educ. 2009, 32, 209-224.

40. Lohman, M.C. A survey of factors influencing the engagement of two professional groups in informal workplace learning activities. Hum. Resour. Dev. Q. 2005, 16, 501-527.

41. Schön, D.A. The Reflective Practitioner: How Professionals Think in Action; Basic Books: New York, NY, USA, 1983.

42. Van Woerkom, M. Critical Reflection at Work: Bridging Individual and Organisational Learning. Ph.D. Thesis, University of Twente, Enschede, The Netherlands, 2003.

43. Barsalou, L.W. Grounded cognition. Annu. Rev. Psychol. 2008, 58, 617-645. 
44. Klarner, P.; Probst, G.; Soparnot, R. Organizational change capacity in public services: The case of the World Health Organization. J. Chang. Manag. 2008, 8, 57-72.

45. Korthagen, F.; Vasalos, A. Levels in reflection: Core reflection as a means to enhance professional growth. Teach. Teach. 2005, 11, 47-71.

46. Eraut, M. Informal learning in the workplace. Stud. Contin. Educ. 2004, 26, 247-273.

47. McArdle, K.; Coutts, N. Taking teachers' continuous professional development (CPD) beyond reflection: Adding shared sense-making and collaborative engagement for professional renewal. Stud. Contin. Educ. 2010, 32, 201-215.

48. Korthagen, F. Linking Practice and Theory: The Pedagogy of Realistic Teacher Education. In Proceedings of the Annual Meeting of the American Educational Research Association, Seattle, WA, USA, 10-14 April 2001.

49. Giles, C.; Hargreaves, A. The sustainability of innovative schools as learning organizations and professional learning communities during standardized reform. Educ. Adm. Q. 2006, 42, 124-156.

50. Timperley, H.; Alton-Lee, A. Reframing teacher professional learning: An alternative policy approach to strengthening valued outcomes for diverse learners. Rev. Res. Educ. 2008, 32, 328-369.

51. Bandura, A. Self-Efficacy: The Exercise of Control; Freeman: New York: NY, USA, 1997.

52. Bandura, A. Perceived self-efficacy in cognitive development and functioning. Educ. Psychol. 1993, 28, 117-148.

53. Caprara, G.V.; Fida, R.; Vecchione, M.; del Bove, G.; Vecchio, G.V.; Barbaranelli, C.; Bandura, A. Longitudinal analysis of the role of perceived self-efficacy for self-regulated learning in academic continuance and achievement. J. Educ. Psychol. 2008, 100, 525-534.

54. Katz-Navon, T.Y.; Erez, M. When collective-and self-efficacy affect team performance the role of task interdependence. Small Group Res. 2005, 36, 437-465.

55. Runhaar, P.R. Promoting Teachers' Professional Development. Ph.D. Thesis, University of Twente, Enschede, The Netherlands, 2008. Available online: http://doc.utwente.n1/60129/1/ thesis_Runhaar,_P.pdf (accessed on 9 February 2011).

56. Walumbwa, F.O.; Lawler, J.J.; Avolio, B.J.; Wang, P.; Shi, K. Transformational leadership and work-related attitudes: The moderating effects of collective and self-efficacy across cultures. J. Leadersh. Organ. Stud. 2005, 11, 2-16.

57. Simbula, S.; Guglielmi, D.; Schaufeli, W.B. A three-wave study of job resources, self-efficacy, and work engagement among Italian schoolteachers. Eur. J. Work Organ. Psychol. 2011, 20, 285-304.

58. Phan, H.P. The development of English and mathematics self-efficacy: A latent growth curve analysis. J. Educ. Res. 2012, 105, 196-209.

59. Malmberg, L.E.; Hagger, H.; Webster, S. Teachers' situation-specific mastery experiences: teacher, student group and lesson effects. Eur. J. Psychol. Educ. 2014, 29, 429-451.

60. Campion, M.A.; Medsker, G.J.; Higgs, A.C. Relations between work groups characteristics and effectiveness: implications for designing effective work groups. Pers. Psychol. 1993, 46, 823-847.

61. Cummings, T.G. Self-regulating work groups: A socio-technical analysis. Acad. Manag. Rev. 1978, 3, 625-634. 
62. De Jong, S.B.; van der Vegt, G.S.; Molleman, E. The relationships among asymmetry in task dependence, perceived helping behavior, and trust. J. Appl. Psychol. 2007, 92, 1625-1637.

63. Van der Vegt, G.; Emans, B.; van de Vliert, E. Team members' affective responses to patterns of intragroup interdependence and job complexity. J. Manag. 2000, 26, 633-655.

64. Wageman, R. Interdependence and group effectiveness. Adm. Sci. Q. 1995, 40, 145-180.

65. Meirink, J.A.; Imants, J.; Meijer, P.C.; Verloop, N. Teacher learning and collaboration in innovative teams. Camb. J. Educ. 2010, 40, 161-181.

66. Staples, D.S.; Webster, J. Exploring the effects of trust, task interdependence and virtualness on knowledge sharing in teams. Inf. Syst. J. 2008, 18, 617-640.

67. Hoy, A.W.; Spero, R.B. Changes in teacher efficacy during the early years of teaching: A comparison of four measures. Teach. Teach. Educ. 2005, 21, 343-356.

68. Mulford, B. Recent Developments in the Field of Educational Leadership: The Challenge of Complexity. In Second International Handbook of Educational Change; Hargreaves, A., Lieberman, A., Fullan, M., Hopkins, D., Eds.; Springer: Dordrecht, The Netherlands, 2010; pp. 187-208.

69. Scribner, J.P.; Hager, D.R.; Warne, T.R. The paradox of professional community: Tales from two high schools. Educ. Adm. Q. 2002, 38, 45-76.

70. Stone, R.W.; Bailey, J.J. Team conflict self-efficacy and outcome expectancy of business students. J. Educ. Bus. 2007, 82, 258-266.

71. Leithwood, K.; Jantzi, D.; Steinbach, R. Changing Leadership for Changing Times; Open University Press: Buckingham, UK, 1999.

72. Avolio, B.J.; Zhu, W.; Kho, W.; Bhata, P. Transformational leadership and organizational commitment: mediating role of psychological empowerment and moderating role of structural distance. J. Organ. Behav. 2004, 25, 951-968.

73. Bass, B.M.; Avolio, B.J. Improving Organizational Effectiveness through Transformational Leadership; Sage: Thousand Oaks, CA, USA, 1994.

74. Leithwood, K.; Sleegers, P. Special Issue of School Effectiveness and School Improvement. Transform. Sch. Leadersh. 2006, 17, 143-227.

75. Yammarino, F.J.; Dionne, S.D.; Schriesheim, C.A.; Dansereau, F. Authentic leadership and positive organizational behavior: A meso, multi-level perspective. Leadersh. Q. 2008, 19, $693-707$.

76. Geijsel, F.P.; Sleegers, P.J.C.; van den Berg, R.M. Transformational leadership and the implementation of large-scale innovation programs. J. Educ. Adm. 1999, 37, 309-328.

77. Dionne, S.D.; Yammarino, F.J.; Atwater, L.E.; Spangler, W.D. Transformational leadership and team performance. J. Organ. Chang. Manag. 2007, 17, 177-193.

78. Geijsel, F.; Sleegers, P.; Leithwood, K.; Jantzi, D. Transformational leadership effects on teachers' commitment and effort toward school reform. J. Educ. Adm. 2003, 41, 228-256.

79. Yost, D.S. Reflection and self-efficacy: Enhancing the retention of qualified teachers from a teacher education perspective. Teach. Educ. Q. 2006, 33, 59-76.

80. Nielsen, K.; Munir, F. How do transformational leaders influence followers' affective wellbeing? Exploring the mediating role of self-efficacy. Work Stress 2009, 23, 313-329. 
81. Tims, M.; Bakker, A.B.; Xanthopoulou, D. Do transformational leaders enhance their followers' daily work engagement? Leadersh. Q. 2011, 22, 121-131.

82. Korek, S.; Felfe, J.; Zäpernick-Rothe, U. Transformational leadership and commitment: A multilevel analysis of group-level influences and mediating processes. Eur. J. Work Organ. Psychol. 2010, 19, 364-387.

83. Nielsen, K.; Randall, R.; Yarker, J.; Brenner, S.-O. The effects of transformational leadership on followers' perceived work characteristics and psychological well-being: A longitudinal study. Work Stress 2008, 22, 16-32.

84. Nir, A.E.; Kranot, N. School principal's leadership style and teachers' self-efficacy. Plan. Chang. 2006, 37, 205.

85. Sun, J.; Leithwood, K. Transformational leadership effects on student achievement. Leadersh. Policy Sch. 2012, 11, 418-451.

86. Moolenaar, N.M.; Sleegers, P.J.C.; Daly, A.J. Teaming up: Linking collaboration networks, collective efficacy, and student achievement. Teach. Teach. Educ. 2012, 28, 251-262.

87. Day, C.; Sammons, P.; Leithwood, K.; Hopkins, D.; Harris, A.; Gu, Q.; Brown, E. Ten Strong Claims about Successful School Leadership; National College for Leadership of Schools and Children's Services: Nottingham, UK, 2010.

88. McArdle, J.J.; Hamagami, F. Latent difference score structural models for linear dynamic analyses with incomplete longitudinal data. Learn. Individ. Differ. 2001, 12, 53-79.

89. Muthén, L.K.; Muthén, B.O. Mplus. User’s Guide, 7th ed.; Muthén \& Muthén: Los Angeles, CA, USA, 1998-2012.

90. Schyns, B.; Von Collani, G. A new self-efficacy scale and its relation to personality constructs and organizational variables. Eur. J. Work Organ. Psychol. 2002, 11, 219-241.

91. McArdle, J.J.; Prindle, J.J. Basic Issues in the Measurement of Change. In APA Handbook of Testing and Assessment in Psychology: Test Theory and Testing and Assessment in Industrial and Organizational Psychology; American Psychological Association: Washington, DC, USA, 2013; pp. 223-243.

92. McArdle, J.J.; Prindle, J.J. A latent change score analysis of a randomized clinical trial in reasoning training. Psychol. Aging 2008, 23, 702-719.

93. Sbarra, D.A.; Allen, J.J. Decomposing depression: On the prospective and reciprocal dynamics of mood and sleep disturbances. J. Abnorm. Psychol. 2009, 118, 171-182.

94. McArdle, J.J.; Hamagami, F.; Meredith, W.; Bradway, K.P. Modeling the dynamic hypotheses of Gf-Gc theory using longitudinal life-span data. Learn. Individ. Differ. 2000, 12, 53-79.

95. Hu, L.; Bentler, P.M. Cutoff criteria for fit indexes in covariance structure analysis: Conventional criteria versus new alternatives. Struct. Equ. Model. 1999, 6, 1-55.

96. Raudenbush, S.W.; Rowan, B.; Cheong, Y.F. Contextual effects on the self-perceived efficacy of high school teachers. Sociol. Educ. 1992, 65, 150-167.

97. Ross, J.A.; Cousins, J.B.; Gadalla, T. Within-teacher predictors of teacher efficacy. Teach. Teach. Educ. 1996, 12, 386-400.

98. Schyns, B. The influence of occupational self-efficacy on the relationship of leadership behavior and preparedness for occupational change. J. Career Dev. 2004, 30, 247-261. 
99. Bandura, A. Social Foundations of Thought and Action: A Social Cognitive Theory; Prentice Hall: Englewood Cliffs, NJ, USA, 1986.

100. Clement, M.; Vandenberghe, R. Teachers' professional development: A solitary or collegial (ad)venture? Teach. Teach. Educ. 2000, 16, 81-101.

101. Little, J. The persistence of privacy: Autonomy and initiative in teachers' professional relations. Teach. Coll. Record 1990, 91, 509-536.

102. Somech, A.; Bogler, R. Antecedents and consequences of teacher organizational and professional commitment. Educ. Adm. Q. 2002, 38, 555-577.

103. Jung, D.I.; Sosik, J.J. Transformational Leadership in Work Groups the Role of Empowerment, Cohesiveness, and Collective-Efficacy on Perceived Group Performance. Small Group Res. 2002, 33, 313-336.

104. Maynard, M.T.; Mathieu, J.E.; Gilson, L.L.; O’Boyle, E.H.; Cigularov, K.P. Drivers and outcomes of team psychological empowerment a meta-analytic review and model test. Organ. Psychol. Rev. 2013, 3, 101-137.

105. Oort, F.J.; Visser, M.R.M.; Sprangers, M.A.G. Formal definitions of measurement bias and explanation bias clarify measurement and conceptual perspectives on response shift. J. Clin. Epidemiol. 2009, 62, 1129-1137.

106. Fullan, M. The New Meaning of Educational Change, 4th ed.; Teachers College Press: New York, NY, USA, 2007.

107. Johnson, D.W.; Johnson, R.T. Energizing learning: The instructional power of conflict. Educ. Res. 2009, 38, 37-51.

108. Spillane, J.P.; Kim, C.M.; Frank, K.A. Instructional Advice and Information Providing and Receiving Behavior in Elementary Schools Exploring Tie Formation as a Building Block in Social Capital Development. Am. Educ. Res. J. 2012, 49, 1112-1145.

109. Tjosvold, D.; Yu, Z.Y.; Hui, C. Team Learning from Mistakes: The Contribution of Cooperative Goals and Problem-Solving. J. Manag. Stud. 2004, 41, 1223-1245.

110. Edmondson, A.C.; Dillon, J.R.; Roloff, K.S. 6 Three Perspectives on Team Learning: Outcome Improvement, Task Mastery, and Group Process. Acad. Manag. Ann. 2007, 1, 269-314.

(C) 2015 by the authors; licensee MDPI, Basel, Switzerland. This article is an open access article distributed under the terms and conditions of the Creative Commons Attribution license (http://creativecommons.org/licenses/by/4.0/). 